Purdue University Purdue e-Pubs

Weldon School of Biomedical Engineering Faculty

Publications

Weldon School of Biomedical Engineering

6-30-2004

\title{
Brain motion and deformation during closed head injury in the presence of cerebrospinal fluid
}

Charles F. Babbs

Purdue University, babbs@purdue.edu

Follow this and additional works at: http://docs.lib.purdue.edu/bmepubs

Part of the Biomedical Engineering and Bioengineering Commons

\section{Recommended Citation}

Babbs, Charles F., "Brain motion and deformation during closed head injury in the presence of cerebrospinal fluid" (2004). Weldon School of Biomedical Engineering Faculty Publications. Paper 41.

http://docs.lib.purdue.edu/bmepubs/41

This document has been made available through Purdue e-Pubs, a service of the Purdue University Libraries. Please contact epubs@purdue.edu for additional information. 
Draft of June 30, 2004

\title{
BRAIN MOTION AND DEFORMATION DURING CLOSED HEAD INJURY IN THE PRESENCE OF CEREBROSPINAL FLUID
}

\author{
CHARLS F. BABBS, MD, PhD \\ Department of Basic Medical Sciences, 1246 Lynn Hall, \\ Purdue University, West Lafayette, IN 47907-1246 USA \\ babbs@purdue.edu
}

\begin{abstract}
This paper presents a new analysis of the physics of closed head injury following brief, intense acceleration of the head. It focuses upon the buoyancy of the brain in cerebrospinal fluid, which protects against damage, the propagation of strain waves through the brain substance, which causes damage, and the concentration of strain in critical anatomic regions, which magnifies damage. Numerical methods are used to create animations or "movies" of brain motion and deformation. Initially a $1 \mathrm{~cm}$ gap filled with cerebrospinal fluid (CSF) separates the brain from the skull. Whole head acceleration induces artificial gravity within the skull. The brain accelerates because its density differs slightly from that of CSF, strikes the inner aspect of the skull, and undergoes viscoelastic deformation. The computed pattern of brain motion correlates well with published high-speed photographic studies. The sites of greatest deformation correlate with sites of greatest pathological damage. This fresh biomechanical analysis allows one to visualize events within the skull during closed head injury and may inspire new approaches to prevention and treatment.
\end{abstract}

Keywords: biomechanics, concussion, diffuse axonal injury, head injury, shear, strain 


\section{Introduction}

Head injuries are common consequences of auto accidents, falls, direct blows to the head, bicycle accidents, fights, and participation in contact sports ${ }^{1,2}$. Nearly two million persons with head injury are medically attended and over 300,000 are hospitalized annually in the USA ${ }^{2}$. One third of these injuries are severe, leading to prolonged coma, death, or survival with permanent neurological impairment ${ }^{3-6}$. The majority of head injuries in man ${ }^{2,6,7}$ and in experimental animal models ${ }^{8,9}$ are mild or moderate, and are produced by acceleration of the head only-without skull fracture ${ }^{9}$. Such nonpenetrating head injuries result in transient loss of consciousness and no permanent neurological deficits. However, repeated mild head injuries (concussions) can and do lead to lasting decrements in problem solving ability, memory, and personality, as well as anatomical lesions in the brain ${ }^{10}$. This paper addresses the problem of what is happening physically inside the skull during closed head injury.

Describing the biomechanics of closed head injury is a classic and still open problem that is difficult to study experimentally. Harmful blunt impacts last only 2 to $20 \mathrm{msec}$.

Subsequent motion of the brain inside the skull lasts just a few seconds and is rarely seen. It has been only partially revealed by studies in animals using high-speed photography through a lucite calvarium or high speed fluoroscopy of implanted radiodense pellets ${ }^{8,11-}$ 13. Only occasionally are the brains of patients sustaining minor head injury examined at autopsy. Fortunately mathematical analysis and modeling of the skull and brain in response to known pulses of head acceleration allow one to study a variety of conditions that are difficult, impossible, or unethical to reproduce in animals or humans.

The challenge of finding the physical mechanism of concussion has attracted a variety of thinkers in the past. Purely descriptive theories of closed head injury ${ }^{14-19}$ specify physical parameters just sufficient for injurious blows, such as critical energy, impulse (force $\mathrm{x}$ time) ${ }^{14,20}$ or acceleration. Transient changes in intracranial pressure, including shock waves, have been explored as mechanisms of closed head injury ${ }^{21-23}$, most interestingly by Gross ${ }^{24}$, who demonstrated with high speed photography the formation and subsequent violent collapse of cavitation bubbles in head-sized flasks subjected to sharp blows. Others have studied more realistic head shaped phantoms approximating the skull ${ }^{18,25-29}$.

Virtually all extant theories do not explicitly include the subarachnoid space and cerebrospinal fluid surrounding the brain; perhaps because of oversimplified notions of the underlying anatomy or because free floating objects are troublesome to deal with by finite element methods ${ }^{30}$. Instead, they often assume a no-slip boundary condition between the skull and the surface of the brain material ${ }^{18,25,28,29}$. Recently Willinge ${ }^{22}$ has called for reexamination of the fluid-structure coupling between brain, CSF, and skull in regard to the biomechanics of head trauma. This change in boundary conditions leads to a fresh and fruitful analysis that provides new insights both for research and for prevention of lasting brain damage after head injury. 


\section{Theory and Methods}

The physics problem at hand is to predict in detail the deformation of brain tissue that results from a particular acceleration of the head, given the geometry of the head and brain, and the physical properties of the brain such as its density and elasticity. Here we shall focus on closed head injury not resulting in skull fracture, that is, injury to the brain occurring when the skull is not distorted in any way. Since the brain is not firmly anchored inside the skull but floating in CSF, it will move toward the site of impact and hit the inner wall of the skull, just as people are thrown forward in a car or train that stops suddenly. What happens before, during, and after brain skull contact is the subject of this paper.

\subsection{Overview and general methods}

The present analysis is done with strict adherence to Newton's Laws of Motion, together with published values for material properties of the brain. In addition we adopt simplified, but not oversimplified, representations of the geometry of the skull, subarachnoid space, cranial cavity, posterior fossa, and falx cerebri. Key aspects of the analysis include use of an internal frame of reference within the skull and the use of multiple mass-spring-damper elements, each responding independently to the pulse of artificial "gravity" caused by whole head acceleration, and each interacting with neighboring viscoelastic elements. Definitions of symbols used in the analysis are provided in Table 1.

Initially the brain is suspended in water density cerebrospinal fluid (CSF). The skull is fixed to a radial beam (the neck), which is free to rotate about a single pivot point at the base of the neck in response to a blow to the head (Figure 1). This geometry is similar to that created in the University of Pennsylvania head injury apparatus ${ }^{31}$, which produces controlled angular acceleration of the head and neck in the sagittal plane. We shall consider the brain to be of homogenous density and elasticity, in keeping with experimental observations ${ }^{32,33}$. We also assume that the brain is isovolumic (i.e. Poisson's ratio $=0.5$ ), so that neither brain volume or CSF volume changes during or immediately after impact.

Viscoelastic properties of brain have been rather well studied over the past 30 years, and consensus values for Young's modulus of elasticity and for an analogously defined energy loss modulus can be gleaned from the literature (Table 2). Despite rather large variability in published values, these data provide a basis for a "standard model" of typical brain viscoelastic properties that is sufficient for present purposes. Brain density data are more consistent. They are summarized in Table 3.

In addition to the use of a constant value for Young's modulus of elasticity, E, we include in some simulations a non-linear regression function for $\mathrm{E}$ depending upon both the 
prevailing local strain and the time rate of change in strain (strain rate). The regression is derived from experimental data of Karol and Miller ${ }^{33}$ and allows tests of the sensitivity of the results to nonlinear tissue elasticity.

Average anatomic dimensions of the adult human skull and brain were obtained from measurements of $12 \mathrm{MRI}$ images of the human head freely available on the Internet. To combine and average these values the maximal internal fronto-occipital diameter of the skull was taken as $18.0 \mathrm{~cm}$, and all other values were expressed relative to this dimension. A summary of critical dimensions for the standard model is presented in Table 4.

\subsection{Acceleration in internal vs. external frames of reference}

In this problem it is helpful to distinguish clearly two frames of reference for motion. The first is the internal frame of reference within the skull. This frame of reference is important because it is the relative motion of brain with respect to the skull that is responsible for closed head injury. The second is the external frame of reference in which the head, neck, and body move. This frame of reference is important because an external blow or fall causes movement of the whole head in this frame. Acceleration of the head in the external frame produces acceleration of the brain in the internal frame in response to an apparent pulse of "artificial gravity" within the skull. The effect is like that felt by a man in a suddenly rising elevator or by a rider in an accelerating vehicle. Acceleration of the rigid skull by an amount $\mathrm{a}(\mathrm{t})$ produces a corresponding artificial gravity within the skull of $-\mathrm{a}(\mathrm{t})$.

Unlike the passenger in a car, however, the brain is suspended in aqueous CSF. If $\rho_{1}$ is CSF density, $\rho_{2}$ is brain density, and $\mathrm{V}_{2}$ is brain volume, then the force of gravity on the brain is $\rho_{2} V_{2}[-a(t)]$, and the buoyancy of the brain is $-\rho_{1} V_{2}[-a(t)]$. Applying

Newton's second law of motion (Force $=$ mass $\mathrm{x}$ acceleration) to the whole brain and ignoring drag",

$$
\left(\rho_{2}-\rho_{1}\right) V_{2}[-a(t)]=\rho_{2} V_{2} \ddot{x}
$$

where $\ddot{\mathrm{x}}$ is the acceleration of the brain with respect to the skull in the direction parallel to whole head acceleration. In turn,

$$
\ddot{x}=-\frac{\left(\rho_{2}-\rho_{1}\right)}{\rho_{2}} \mathrm{a}(\mathrm{t})=\frac{\left(\rho_{1}-\rho_{2}\right)}{\rho_{2}} \mathrm{a}(\mathrm{t})
$$

in the internal frame of reference of the skull. This acceleration is substantially less than the acceleration, $\mathrm{a}(\mathrm{t})$, of the head as a whole. If brain and CSF density were perfectly

\footnotetext{
\# It is reasonable to ignore the effects of viscous drag on the brain from CSF water, because the distance traveled by the brain through CSF is short and brain speeds relative to the skull are limited over this distance.
} 
matched there would be zero acceleration of the brain with respect to the skull. In reality, brain density is approximately 1.046 and CSF density is approximately $1.00^{32,34,35}$

(Table 3), so internal brain acceleration is about 5 percent of external head acceleration.

In cases of rotational acceleration, $\ddot{\theta}$, of the skull (Figure 1 ) distance $\mathrm{R}=\mathrm{r}_{\text {neck }}+\mathrm{y}$ from the pivot point for rotation of the neck, the magnitude of external acceleration is given by

$$
a(R, t)=\sqrt{(R \ddot{\theta})^{2}+\left(R \dot{\theta}^{2}\right)^{2}}=R \ddot{\theta} \sqrt{1+\left(\frac{\dot{\theta}^{2}}{\ddot{\theta}}\right)^{2}} \cong R \ddot{\theta}
$$

The approximation is a good one, since it can be shown for head injury scenarios that the rightmost square root term in (3) is between 1.00 and 1.01 in practical cases. The duration of impact is so brief that the angular velocity, $\dot{\theta}$, remains small. Hence for rotation of the whole head and neck it is a simple matter to convert to the corresponding linear acceleration for a particular brain region (Figure 1, legend).

\subsection{Temporal frames of reference}

To further compartmentalize the problem, it is helpful to consider brain motion with respect to the skull in several phases in time: a free-floating phase, a compression phase, and a recoil phase. In phase 1 the brain moves toward the skull suspended in CSF but has not yet hit the inner wall of the skull. In phase 2 the leading edge of the brain touches the skull, and the brain becomes compressed against the side of contact. Accompanying this axial compression there is lateral expansion, which may be limited by the bounds of the skull. Lateral expansion happens when compression of material in one dimension causes elongation or stretch of the material in the other two dimensions, according to Poisson's ratio $^{36,37}$. In Phase 3 there is recoil of the brain from maximal compression with reversal of its direction of motion relative to the skull. Phase 3 is then succeeded by another freefloating phase with motion of the brain toward the opposite side of the skull, where a second impact can occur. Several such cycles of compression and recoil can occur, with gradual damping of the motion by viscous forces.

\subsection{Motion of the brain before impact with the skull}

Computation of brain motion with respect to the skull in Phase 1 is straightforward for external head accelerations of magnitude $\mathrm{a}(\mathrm{t})$ and duration $\tau$, as long as $\tau$ is less than the critical duration, $\hat{\tau}$, when the leading edge of the brain hits the skull. Here the critical duration $\hat{\tau}=\sqrt{2 \mathrm{~s} / \mathrm{g}}$, where $\mathrm{s}$ is the width of the CSF between the brain and the inner aspect of the skull and

$$
g=\frac{\left(\rho_{1}-\rho_{2}\right)}{\rho_{2}} \cdot \frac{1}{\tau} \int_{0}^{\tau} \mathrm{a}(\mathrm{t}) \mathrm{dt}
$$


which is the mean internal acceleration of the brain with respect to the skull. Use of the mean acceleration over time to represent blows to the head is well precedented in the literature ${ }^{19}$ and is sufficient for present purposes. Here CSF width, s, is a given anatomic parameter of the system which is approximately equal to $1 \mathrm{~cm}$ in humans. For most practical values of head acceleration it turns out that $\tau$ is less than $\hat{\tau}=\sqrt{2 \mathrm{~s} / \mathrm{g}}$, in which case we refer to these impacts as "short duration" blows. For short duration blows the instantaneous velocity of the brain is $\mathrm{gt}$ for times, $\mathrm{t}$, less than $\tau$, and then remains constant at $g \tau$ for times between $\tau$ and $\hat{\tau}$. The final velocity of the whole brain toward the skull in the internal frame of reference is then simply $v_{0}=g \tau$, where the subscript 0 refers to the instant of brain-skull contact (Figure 2, top).

\subsection{Motion of the brain after impact with the skull}

\subsubsection{Analytical methods}

During Phase 2 of brain motion there is propagation of a compressive strain wave through the whole brain, accompanied by lateral expansion in dimensions orthogonal to the compression. Note that strain waves discussed herein are not the same as sound waves or pressure waves propagating through tissue water. Strain waves are waves of deformation of a soft elastic material (the brain) floating in CSF water. These waves propagate much slower than do sound waves in water. In their 1994 textbook, The Mechanisms of Continua and Wave Dynamics, Brekhovskikh and Gancharov ${ }^{38}$ have brilliantly described the exact nature of the compressive strain wave in a block of elastic material impacting a rigid wall at constant velocity, $\mathrm{v}_{0}$, in one dimension. They showed that for a column comprised of a material of density, $\rho$, having uniform stiffness (Young's modulus of elasticity), E, and hitting a solid wall with initial velocity, $\mathrm{v}_{0}$, a wave of compressive strain is propagated through the column in a particular last-in/first-out pattern.

Figure 2 illustrates Brekhovskikh-Gancharov compression of a uniform onedimensional model of the brain. At time $t=0$ an elastic column of length, $\mathrm{L}$, hits a rigid wall with initial velocity $\mathrm{v}_{0}$. The wall acts on the column with a force that initiates a strain wave that propagates along the column with velocity, $c=\sqrt{E / \rho}$. For this idealized case of no viscous damping or energy loss, the compression is of uniform degree in the compressed region and is zero elsewhere. That is, there is a rectangular wave of compression and lateral expansion, traveling from the wall toward the free end of the column. At time $\mathrm{t}=\mathrm{L} / \mathrm{c}$ the entire column is uniformly compressed. The amount of compressive strain is simply $\mathrm{v}_{0} / \mathrm{c}$. Because we can compute $\mathrm{v}_{0}=\mathrm{g} \tau$, as just described, it is a simple matter to find the value of compressive strain. Moreover, if the brain material is isovolumic during deformation (Poisson's ratio $=0.5$ ), then the expansive strain perpendicular to $\mathrm{v}_{0}$ is equal to $0.5 \mathrm{v}_{0} / \mathrm{c}$. 
Thereafter, for times $\mathrm{L} / \mathrm{c}<\mathrm{t}<2 \mathrm{~L} / \mathrm{c}$ there is recoil, in reverse order, beginning with the free end. At time $t=2 \mathrm{~L} / \mathrm{c}$ the entire column recoils with velocity $\mathrm{v}_{0}$. In this idealized case, our brain model, having suffered a "coup" would drift at velocity $v_{0}$ toward the other side of the skull where it would undergo a mirror image deformation or "contrecoup". Without energy loss due to damping, the cycle would be repeated indefinitely. ${ }^{* *}$ This one-dimensional analytical model captures several essential aspects of brain motion in closed head injury. When supplied with particular values of $E$ and $\rho$ for brain, it can be used for validation of more computer codes representing more complex situations.

\subsubsection{A numerical methods}

Brekhovskikh - Gancharov analysis, however, does not include effects of viscous damping or predict motion in two or three dimensions for complex geometries. To better characterize both translation and rotation of the brain and to permit visualization of deformation in two dimensions, a numerical model was developed. The brain is regarded as a modified Voigt/Maxwell body ${ }^{37}$ including discrete mass elements connected by both springs and dampers in a rectangular 8-way mesh. The mathematics are specifically designed for strain analysis with significant relative motion of the elements. At rest the brain is represented by a rectangular matrix of masses, $m_{i, j}$, which may be trimmed or sculpted to represent a cylinder, ellipsoid, or other curved shape in two dimensions. It is helpful to represent the 8 neighbors of mass $m_{i, j}$ by directions $N, E, S, W$, named for north, east, south, and west, and similarly for NE, NW, SE, and SW. Each mass is connected to neighbors $\mathrm{N}, \mathrm{E}, \mathrm{S}, \mathrm{W}$ by a massless springs having spring constant, $\mathrm{k}$, and parallel dampers having damping constant, $\mu$. On the diagonals each mass is connected to neighbors NE, NW, SE, and SW by a massless springs having spring constant, $\mathrm{k}_{\mathrm{d}}$, and parallel dampers of damping constant, $\mu_{\mathrm{d}}$. (For simplicity, the diagonal connections are not shown in the meshes drawn in Figures 3 through 7.) At rest the component masses are spaced distance, $\mathrm{d}_{0}$, apart in the N-S and E-W dimensions and by distance $\sqrt{2} \mathrm{~d}_{0}$ on the diagonals. The value of each interior mass is $m=\rho d_{0}^{3}$. Edge masses have value $\mathrm{m} / 2$ and corner masses have value $\mathrm{m} / 4$. In the models having radial symmetry, the mass of each ring is related to its radial distance from the central axis. The location of the center of each mass is called a node.

In the present research we wish to track the motion of each node in time during and after a brief forceful acceleration of the head. For an interior mass $\mathrm{i}, \mathrm{j}$ the $\mathrm{x}$-component of

\footnotetext{
${ }^{* *}$ In the absence of damping it is easy to show conservation of energy at maximum crunch, when axial brain length is diminished by amount $\Delta \mathrm{L}$. The stored energy at maximum crunch is $\mathrm{U}=\frac{1}{2} \mathrm{k}(\Delta \mathrm{L})^{2}$, where $\mathrm{k}=\frac{\mathrm{EA}}{\mathrm{L}}$ is the spring constant for the elastic material of length $\mathrm{L}$ and cross section $\mathrm{A}$, and $\Delta \mathrm{L}=\frac{\mathrm{v}_{0}}{\mathrm{c}} \mathrm{L}=\mathrm{v}_{0} \mathrm{~L} \sqrt{\frac{\rho}{\mathrm{E}}}$ at maximum crunch. Hence, $\mathrm{U}=\frac{1}{2} \frac{\mathrm{EA}}{\mathrm{L}} \frac{\mathrm{v}_{0}^{2} \mathrm{~L}^{2} \rho}{\mathrm{E}}=\frac{1}{2} \mathrm{mv}_{0}^{2}$, which is the kinetic energy of the original bar of total mass, $\mathrm{m}$, moving at $\mathrm{v}_{0}$ toward the wall. A similar approach shows conservation of energy at all times during a cycle of impact, compression, and recoil.
} 
acceleration depends upon the sum of applied forces due to local gravity, neighboring springs, and neighboring dampers,

$m \ddot{x}_{i, j}=F_{x g}+F_{x k}+F_{x \mu}$.

The orthogonal (y) component of acceleration is given by

$m \ddot{y}_{i, j}=F_{y g}+F_{y k}+F_{y \mu}$.

These expressions and the similar ones for edge nodes of mass $\mathrm{m} / 2$ and for corner nodes of mass $\mathrm{m} / 4$ can be solved for the acceleration of each node in the array as follows.

\subsubsection{Force computation}

Let horizontal distances between node $\mathrm{i}, \mathrm{j}$ and its neighbors be defined as

$$
\begin{aligned}
& \Delta x_{N}=x_{i, j+1}-x_{i, j}, \\
& \Delta x_{N E}=x_{i+1, j+1}-x_{i, j}, \\
& \Delta x_{E}=x_{i+1, j}-x_{i, j}, \text { etc. }
\end{aligned}
$$

Let vertical distances between node $\mathrm{i}, \mathrm{j}$ and its neighbors be defined as

$$
\begin{aligned}
& \Delta y_{N}=y_{i, j+1}-y_{i, j}, \\
& \Delta y_{N E}=y_{i+1, j+1}-y_{i, j}, \\
& \Delta y_{E}=y_{i+1, j}-y_{i, j}, \text { etc. }
\end{aligned}
$$

Let straight line distances between node $\mathrm{i}, \mathrm{j}$ and its neighbors be defined as

$$
\begin{aligned}
& \mathrm{d}_{\mathrm{N}}=\sqrt{\left(\Delta \mathrm{x}_{\mathrm{N}}\right)^{2}+\left(\Delta \mathrm{y}_{\mathrm{N}}\right)^{2}}, \\
& \mathrm{~d}_{\mathrm{NE}}=\sqrt{\left(\Delta \mathrm{x}_{\mathrm{NE}}\right)^{2}+\left(\Delta \mathrm{y}_{\mathrm{NE}}\right)^{2}}, \\
& \mathrm{~d}_{\mathrm{E}}=\sqrt{\left(\Delta \mathrm{x}_{\mathrm{E}}\right)^{2}+\left(\Delta \mathrm{y}_{\mathrm{E}}\right)^{2}}, \text { etc. }
\end{aligned}
$$

Now the $\mathrm{x}$-component of acceleration is

$$
\ddot{x}_{i, j}=\frac{1}{m}\left(F_{x g}+F_{x k}+F_{x \mu}\right)
$$

where with reference to Figure 1

$$
F_{x g}=a(t) \frac{\rho-\rho_{C S F}}{\rho} \cdot \frac{y_{i, j}-r_{\text {neck }}}{r_{\text {neck }}}
$$


and as shown in Appendix 1,

$$
\begin{aligned}
\mathrm{F}_{\mathrm{xk}} & =\mathrm{k} \Delta \mathrm{x}_{\mathrm{N}}\left(1-\mathrm{d}_{0} / \mathrm{d}_{\mathrm{N}}\right)+\mathrm{k} \Delta \mathrm{x}_{\mathrm{E}}\left(1-\mathrm{d}_{0} / \mathrm{d}_{\mathrm{E}}\right) \\
& +\mathrm{k} \Delta \mathrm{x}_{\mathrm{S}}\left(1-\mathrm{d}_{0} / \mathrm{d}_{\mathrm{S}}\right)+\mathrm{k} \Delta \mathrm{x}_{\mathrm{W}}\left(1-\mathrm{d}_{0} / \mathrm{d}_{\mathrm{W}}\right) \\
& +\mathrm{k}_{\mathrm{d}} \Delta \mathrm{x}_{\mathrm{NE}}\left(1-\mathrm{d}_{0} / \mathrm{d}_{\mathrm{NE}}\right)+\mathrm{k}_{\mathrm{d}} \Delta \mathrm{x}_{\mathrm{NW}}\left(1-\mathrm{d}_{0} / \mathrm{d}_{\mathrm{NW}}\right) \\
& +\mathrm{k}_{\mathrm{d}} \Delta \mathrm{x}_{\mathrm{SE}}\left(1-\mathrm{d}_{0} / \mathrm{d}_{\mathrm{SE}}\right)+\mathrm{k}_{\mathrm{d}} \Delta \mathrm{x}_{\mathrm{SW}}\left(1-\mathrm{d}_{0} / \mathrm{d}_{\mathrm{SW}}\right)
\end{aligned}
$$

and

$$
\begin{aligned}
\mathrm{F}_{\mathrm{x} \mu} & =\mu \Delta \mathrm{x}_{\mathrm{N}} \dot{\mathrm{d}}_{\mathrm{N}} / \mathrm{d}_{\mathrm{N}}+\mu \Delta \mathrm{x}_{\mathrm{E}} \dot{\mathrm{d}}_{\mathrm{E}} / \mathrm{d}_{\mathrm{E}} \\
& +\mu \Delta \mathrm{x}_{\mathrm{S}} \dot{\mathrm{d}}_{\mathrm{S}} / \mathrm{d}_{\mathrm{S}}+\mu \Delta \mathrm{x}_{\mathrm{W}} \dot{\mathrm{d}}_{\mathrm{W}} / \mathrm{d}_{\mathrm{W}} \\
& +\mu_{\mathrm{d}} \Delta \mathrm{x}_{\mathrm{NE}} \dot{\mathrm{d}}_{\mathrm{NE}} / \mathrm{d}_{\mathrm{NE}}+\mu_{\mathrm{d}} \Delta \mathrm{x}_{\mathrm{NW}} \dot{\mathrm{d}}_{\mathrm{NW}} / \mathrm{d}_{\mathrm{NW}} \\
& +\mu_{\mathrm{d}} \Delta \mathrm{x}_{\mathrm{SE}} \dot{\mathrm{d}}_{\mathrm{SE}} / \mathrm{d}_{\mathrm{SE}}+\mu_{\mathrm{d}} \Delta \mathrm{x}_{\mathrm{SW}} \dot{\mathrm{d}}_{\mathrm{SW}} / \mathrm{d}_{\mathrm{SW}}
\end{aligned}
$$

with the time rate of change of distance

$$
\dot{\mathrm{d}}_{\mathrm{N}}=\frac{1}{\mathrm{~d}_{\mathrm{N}}}\left(\Delta \mathrm{x}_{\mathrm{N}} \cdot \frac{\mathrm{d}}{\mathrm{dt}} \Delta \mathrm{x}_{\mathrm{N}}+\Delta \mathrm{y}_{\mathrm{N}} \cdot \frac{\mathrm{d}}{\mathrm{dt}} \Delta \mathrm{y}_{\mathrm{N}}\right),
$$

and similarly for the other directions.

The orthogonal y-component of acceleration is

$$
\ddot{y}_{i, j}=\frac{1}{m}\left(F_{y g}+F_{y k}+F_{y \mu}\right),
$$

where

$$
\mathrm{F}_{\mathrm{yg}}=\mathrm{a}(\mathrm{t}) \frac{\rho-\rho_{\mathrm{CSF}}}{\rho} \cdot \frac{\mathrm{x}_{\mathrm{i}, \mathrm{j}}}{\mathrm{r}_{\text {neck }}}
$$

$F_{y k}$ and $F_{y \mu}$ are calculated similarly to (6c) and (6d) with the substitution of $\Delta y$ values for the corresponding $\Delta \mathrm{x}$ values.

The spring constants for the 8-way mesh were scaled such that the mesh exhibited the proper ratios between plane stress and plain strain and between shear stress and shear strain for a classical uniform elastic material having Young's E and Poisson's ratio $v$, namely $\mathrm{E}=$ plane stress/plane strain, and $\mathrm{E} /(2(1+v))=$ shear stress/shear strain. These constraints led to the expressions 


$$
\begin{aligned}
& \mathrm{k} \approx \frac{\mathrm{AE}}{\mathrm{s}}\left(\frac{1+3 v}{2(1+v)}\right) \cdot(1+\phi \varepsilon), \text { and } \mathrm{k}_{\mathrm{d}} \approx \frac{\mathrm{k}}{1+3 v}, \\
& \mu \approx \frac{\mathrm{AD}}{\mathrm{s}}\left(\frac{1+3 v}{2(1+v)}\right) \cdot(1+\phi \varepsilon), \text { and } \mu_{\mathrm{d}} \approx \frac{\mu}{1+3 v},
\end{aligned}
$$

where $\phi$ is a small constant on the order of $1 / 3$ and $\varepsilon$ is the local compressive strain in the direction of the $\mathrm{x}$ or $\mathrm{y}$ force component. These expressions are derived in Appendix 2. In the present application for Poisson's ratio $v=0.5$, we have $\mathrm{k}=0.83 \cdot(\mathrm{AE} / \mathrm{s}) \cdot(1+0.29 \varepsilon)$ and $\mathrm{k}_{\mathrm{d}}=0.33 \cdot(\mathrm{AE} / \mathrm{s}) \cdot(1+0.29 \varepsilon)$, and similarly for $\mu$ and $\mu_{\mathrm{d}}$

The $(1+\phi \varepsilon)$ corrections for spring constants maintain a defined stiffness, despite significant compressive or expansive strains up to about 50\%. They account for the change in the vertical and horizontal force components produced by the diagonal elements as their orientation changes with deformation.

\subsubsection{Integration of the equations of motion}

Once these complexities of the force components are dealt with and the $\mathrm{x}$ and $\mathrm{y}$ components of acceleration for each node are known, the remainder of computations to describe the motion of each node are straightforward.

Beginning with initial conditions at $\mathrm{t}=0$, the component accelerations are doubly integrated using a truncated Taylor's series approach to extrapolate from time $t$ to time $\mathrm{t}+\Delta \mathrm{t}$, namely

$$
\begin{aligned}
& \dot{x}(\mathrm{t}+\Delta \mathrm{t})=\ddot{x}(\mathrm{t}) \Delta \mathrm{t} \\
& \mathrm{x}(\mathrm{t}+\Delta \mathrm{t})=\mathrm{x}(\mathrm{t})+\dot{x}(\mathrm{t}) \Delta \mathrm{t}+\frac{1}{2} \ddot{\mathrm{x}}(\mathrm{t})(\Delta \mathrm{t})^{2},
\end{aligned}
$$

and similarly for $\dot{y}(t+\Delta t)$ and $y(t+\Delta t)$. Results were displayed in computer animations showing motion of all nodes in the model as a function of time. The time step of integration, $\Delta \mathrm{t}$, was selected such that $\mathrm{c} \Delta \mathrm{t}<<\mathrm{d}_{0}$ to permit faithful representation of strain wave propagation. Motion of the nodes was constrained when they hit the wall of the surrounding skull.

\subsection{Computer hardware and software}

The forgoing numerical model was implemented in Visual Basic code within an Excel spreadsheet on ordinary personal computers operating under Microsoft Windows 2000. 
Visual Basic provides a highly portable platform for custom animations to visualize brain motion. Computer code was validated by comparison with simple test cases, including the motion of two masses, the one dimensional Brekhovskikh-Gancharov impact problem, and a constant gravity problem in one dimension, for which analytical solutions are available. The resulting code was also validated by testing for conservation of energy in the absence of damping.

\subsection{Geometric models for frontal and lateral blows to the head}

To study the physics of closed head injury one can create a family of two-dimensional geometric models of the skull and brain. The first is a rectangular model that recapitulates the analytical model of Brekhovskikh and Gancharov. Comparison of numerical and analytical results allows validation of computer code and exploration of the effects of viscous damping. The next is a true ellipsoidal model, in which radial symmetry is incorporated to explore the effects of tapering of cross sectional area along the axis of acceleration. The model brain now has a football or rugby ball shape. Acceleration is axial only, and strain concentration at the ends of the model can be studied.

The third model is an elliptical cylinder. This model would appear in three dimensions as an oval cake of uniform thickness, viewed from above. It can be accelerated along its long axis and also rotated within the CSF containing subarachnoid space. A larger version can represent the cerebral hemispheres, and a smaller version can represent the cerebellum and pons in the posterior fossa of the skull. A truncated version (i.e. an oval cake cut off at the bottom) provides a more realistic representation of the frontal lobes of the brain in sagittal section. A final quarter oval model can be used to represent one half of a coronal section of the brain, including the falx cerebri. It can be used to demonstrate local strain concentration at the inferior edge of the falx in the region of the corpus callosum. Specific dimensions and tissue parameters for the various geometric models of the brain, described next, are indicated in Tables 4 and 5.

\subsection{Making movies}

To visualize motion of a generalized 2D model of the brain, one can first create a rectangular array of masses supported in an 8-way mesh of springs and dampers. Then a boundary function is defined, such as an ellipse, and nodes outside the boundary are pruned. A rigid boundary of the skull is defined with a spacing equal to the CSF width. At times $t>0$ the model moves inside the skull in response to an impulse of acceleration. If points move outside the boundary of the skull, they can be either brought back to previous position and stopped (velocity $=0$ ) as a no-slip boundary condition, or they can be brought back to a new position at the boundary with slippage parallel to the boundary.

The nodes are represented in visual basic as small rectangles, joined in a mesh by connectors. One can use the IncrementLeft() and IncrementTop() functions to move 
nodes around on a high resolution screen. The zoom factor for the screen was set to $25 \%$ or less to minimize discretization error in the screen positions of the nodes. The display was erased and re-drawn at the end of the simulation time to provide accurate final positions, which are reproduced in the figures.

\section{Results}

\subsection{Overview: three components of brain deformation}

Description of brain deformation during closed head injury is aided by considering separately three components. The first is the occurrence of strain waves along the main axis of linear acceleration of the head. The second is strain concentration caused by local geometry. The third is the occurrence of transverse strain waves caused by rotational acceleration of the head. These three effects summate in mathematical models to produce complex motion in time and space that, as we shall see, are consistent with experimental observations. The motion is much easier to study in mathematical models, however, than in animal models.

\subsection{Strain waves caused by linear acceleration}

Strain waves associated with brain-skull impact can be appreciated in one dimension and are well visualized by computer animations, such as those reproduced in Figures 3 and 4. In Figure 3, the outer solid rectangle indicates the inner aspect of the skull. The inner mesh represents a sagittal section of a cerebral hemisphere. The axis of acceleration is horizontal. A blow strikes the brain model on the right, causing initial acceleration of the brain from left to right with respect to the skull. The elapsed time from onset of acceleration at $\mathrm{t}=0$ is indicated in the figure legend.

In Figure 3 the brain at rest (a) suddenly experiences a short, intense external acceleration of the skull $1000 \mathrm{~m} / \mathrm{sec}^{2}$, lasting 0.01 second. Such accelerations are at the threshold for concussion in animals and in man ${ }^{16,39}$. At $t=0.03 \mathrm{sec}(\mathrm{b})$ the brain hits the skull and a compression wave begins to propagate through the model. There is compression to maximum crunch (c), followed by rebound with lift off in the opposite direction, migration across the CSF containing subarachnoid space, contact on the opposite side, and another cycle of compression (d). With successive cycles compressive strain amplitude decreases, owing to the effect of damping. This pattern of deformation suggests that, in part, closed head injury is likely to affect the brain globally and diffusely, because compressive strain waves propagate through the entire brain.

\subsection{Strain concentration at the poles}

Figure 4(a) shows a similar sequence for a rugby ball shaped ellipsoidal model with radial symmetry about the long axis of the ellipsoid. The deformation of the cerebral 
hemispheres at maximal crunch is shown. The amount of compressive strain at the pole is much greater than in the mid portions of the brain for this geometry. Strain concentration happens because there is less material at the pole to absorb the energy of the whole brain striking a rigid wall. A similar effect is seen for the elliptical cylinder model subjected to a purely axial acceleration in Figure 4 (b). When the simulation is repeated using non-linear expression for Young's modulus, E, of brain material as observed by Miller ${ }^{33}$, the results in Figure 4(c) are obtained at maximum crunch. These are quite similar to those in the simple linear model. In this case increased stiffness at larger compressive strains offsets decreased stiffness at smaller compressive strains.

\subsection{Rotational and translational acceleration}

In Figure 5 we add the orthogonal y-component of acceleration caused by rotation of the head about a pivot point at the base of the neck, as shown in Figure 1. The truncated elliptical cylinder model represents a parasagittal section of one cerebral hemisphere. The flat bottom portion represents the base of the skull and/or roof of tentorium cerebelli. The animation sequence shows results of a frontal blow to the forehead of a person facing rightward. There is both linear acceleration and backward (counterclockwise) rotation of the whole head, which causes forward movement and clockwise rotation of the brain within the skull. Maximal crunch at both coup and contrecoup points in time is shown. There is combined compressive strain in both $\mathrm{x}$ and $\mathrm{y}$ dimensions as well as force concentration at the poles.

Figure 6 is a similar model of the structures in the posterior fossa, that is, pons and cerebellum. A frontal blow comes from the right. Here the axis of the neck crosses the model more anteriorly. The right hand third of the model represents the pons and the left hand two thirds of the model represent the cerebellum. Initial coup injury causes extensive compression of the pons (b). This anatomic force concentration in the midbrain could well explain the high incidence of injury to the transverse fibers of the pons $3,4,6,9$, $31,40,41$ and also the high incidence of unconsciousness associated with such impacts, owing to local involvement of the reticular formation associated with sleep-wake cycles and alertness. The contrecoup phase (c) involves compression of the cerebellum to a somewhat lesser degree. Injury here could be related to staggering behavior and ataxia observed following blows to the head (the "punch drunk" phenomenon).

Figure 7 represents a coronal section of one cerebral hemisphere in the region of the corpus callosum. A threshold concussive blow to the side of the head causes an initial coup phase (a), followed by a contrecoup phase that is partially restrained by the falx cerebri only in the top half of the mid-sagittal plane (b). As a result the strain pattern at contrecoup shows shearing in regions near the bottom edge of the falx, represented by the bottom row of nodes. This is where the crossing fibers of the corpus callosum (not shown) connect the two hemispheres. The extra shear strain near the bottom edge of the falx in the region of the corpus callosum correlates with known pathology of closed head injury in this region. 


\section{Discussion}

The present simulations indicate that the buoyant properties of the CSF and the viscoelastic properties of brain tissue play important roles in the biomechanics of closed head injury. The simulations make many specific predictions concerning brain motion and areas of highest strain concentration that can be correlated with known experimental observations to provide validation of the model and the presumed underlying physics.

\subsection{Validation by direct observation of brain motion}

Although rare and difficult to reproduce today, direct observations of the motion of the brain within the skull during closed head injury in primates have been made after surgical replacement of the calvarium with a transparent plastic material ${ }^{11,13}$. Pudenz and Shelden ${ }^{11}$ used a compressed air gun to deliver blows to the forehead of anesthetized monkeys and visualized whole brain motion with high speed photography at 16 frames/sec. There was backward rotation of the head and neck (as in Figures 1 and 5), causing both linear and angular acceleration. Using an external frame of reference, they observed that initially during impact the brain stands still and the skull moves backward: "There was a momentary pause before the surface convolutions followed the skull through the sagittal plane of displacement". They also described brain motion as a rotational glide of surface convolutions. This description fits predictions in the present paper for whole brain motion in two dimensions. The final movements of the brain consisted of anteroposterior undulations of diminishing amplitude, analogous to those in Figure 3. Similar motion of the cerebellum and medulla within the posterior fossa has also been directly observed ${ }^{12}$.

An important additional finding of Pudenz and Shelden ${ }^{11}$ supports the critical role of the CSF. They observed considerable "dampening effect of the cerebrospinal fluid" on brain displacement. In particular, they noted that "an identical blow delivered to the same animal after withdrawal of cerebrospinal fluid was attended by considerable increase in the amplitude convolutional glide" and that "the final oscillations of the brain were especially striking in this case".

Later Gosch and coworkers were able to take high speed photographs through a Lexan calvarium of a strain wave passing through the brain of an anesthetized Rhesus monkey subjected to blunt impact ${ }^{13}$. They found that "The cerebral mass maintains momentum of acceleration in relation to the skull, which results in concomitant compression of the intracranial contents". A maximal compressive strain of 20 percent was directly observable from published photographs of the brain surface ${ }^{13}$. The pattern of compression is similar to that shown in Figure 2 for compressive strain waves in that the absolute forward motion of brain indentations (sulci) farther from the impact point is greater than that of sulci closer to the impact point. Moreover, from the images taken $1 / 200 \mathrm{sec}$ apart one can estimate the speed of travel of the compression wave at approximately $20 \mathrm{~mm} / 5 \mathrm{msec}=4 \mathrm{~m} / \mathrm{sec}$. From theory just presented and published 
values of Young's modulus of brain, one would expect the compression wave velocity to

be about $\sqrt{\mathrm{E} / \rho}=\sqrt{10000 / 1000}=3.1 \mathrm{~m} / \mathrm{sec}$, which is in reasonable agreement with observation.

\subsection{Validation by comparison with known pathology of closed head injury}

The passage of strain waves uniformly through a rectangular brain model correlates with the "diffuse axonal injury" (DAI) observed in persons suffering head injuries ${ }^{3,5,6,31,42,43}$, especially injuries accompanied by coma lasting more than 24 hours. The concept of DAI also fits with the functional impairment of global cortical function observed after mild to moderate head injury, including memory impairment and difficulty returning to work $^{10}$.

In addition to DAI, the pathology of closed head injury in animals and in humans includes particular sites focal contusion and hemorrhage. These include the coup point at the impact pole ${ }^{3,8,9}$ and to a lesser extent the contrecoup point at the opposite pole ${ }^{4,12}$, the pons and cerebellar peduncles in the posterior fossa ${ }^{3,4,6,9,31,40,41}$, and the transverse fibers of the corpus callosum following lateral blows to the head ${ }^{3,4,9,40,41}$. Lesions to the pons also correlated with the presence of unconsciousness, since the reticular formation that is recognized as responsible for consciousness traverses this region. The present analysis of the physics of closed head injury shows that it is indeed in these areas where extra amounts of compressive strain occur, owing to the local geometry of the cranial cavity.

\subsection{Validation by comparison with known injurious and safe accelerations}

Some brain acceleration occurs during normal daily activities such as running and jumping, which is evidently harmless. Accordingly, there must be a threshold for truly injurious compressive strain, which we denote here as $\varepsilon^{*}$. It is interesting to compare accelerations required to produce a particular level of strain - either globally or just at the poles - with established head injury criteria. These criteria are defined in terms of the acceleration strength and acceleration duration required to produce concussion. (Both higher accelerations for shorter durations and lower accelerations for longer durations produce equivalent effects.)

Simple Brekhovskikh - Gancharov analysis predicts a strength-duration curve for blows sufficient to produce a given harmful compressive strain, $\varepsilon^{*}$. Mean internal acceleration multiplied by acceleration duration gives initial velocity, $\mathrm{v}_{0}$, of the brain within the skull. For example, if critical compressive strain $\varepsilon^{*}=\mathrm{v}_{0} / \mathrm{c} \approx 0.4$, then a $40 \%$ intracranial compression, accompanied by 20 percent stretch for Poisson's ratio $=0.5$, would occur during blows at the concussive threshold. This expression provides a basis for comparison of theory and experiment. 
An analysis of concussion threshold data in monkeys was done by Ommaya ${ }^{15}$, who found that any blow in monkeys producing an angular head acceleration of $>250$ radians/sec produces physiological concussion. Taking the neck radius for a monkey as about 0.1 meter, the linear external head acceleration associated with 250 radians/sec head and neck rotational velocity is

$$
\overline{\mathrm{a}} \cdot \Delta \mathrm{t}=\mathrm{v}_{\text {head }}=0.1 \frac{\mathrm{m}}{\text { radian }} \times 250 \frac{\text { radian }}{\mathrm{sec}}=25 \frac{\mathrm{m}}{\mathrm{sec}}
$$

at threshold external head velocity. Since internal acceleration of the brain with respect to the skull is about 5 percent of external head acceleration, given the weight to the brain in cerebrospinal fluid, then

$$
\mathrm{v}_{\text {brain }} \approx 0.05 \cdot 25 \frac{\mathrm{m}}{\mathrm{sec}}=1.25 \frac{\mathrm{m}}{\mathrm{sec}}
$$

would be the critical velocity of the brain toward the skull. According to Brekhovskikh - Gancharov theory, this internal brain velocity would produce a critical compressive strain of

$$
\varepsilon^{*}=\frac{\mathrm{v}}{\mathrm{c}}=\frac{1.25 \mathrm{~m} / \mathrm{sec}}{3.1 \mathrm{~m} / \mathrm{sec}}=0.4
$$

which would produce corresponding stretch of 0.2 in orthogonal dimensions. If we accept the premise that axonal injury happens when elongation strain exceeds a threshold such as 20 percent, this value agrees well with experimental observations of functional or morphological impairment after stretching of squid axons ${ }^{44}$, guinea pig optic nerves ${ }^{45}$, and sciatic nerves of frogs $\mathrm{s}^{46}$. Thus the present buoyancy-strain wave model predicts a strength duration curve for blows sufficient to produce concussion in experimental primates that is quite similar to that actually observed, if one chooses a critical strain threshold of 40 percent compression or 20 percent stretch.

A similar calculation for the range of safe head accelerations can provide another point of validation. Adams ${ }^{41}$ noted that severe diffuse axonal injury in humans happening as a result of falls occurs only after falls from substantially greater than a person's own height - for example, from a ladder, bridge, elevator shaft, or even a mountain ${ }^{41}$ ! As before, we expect from theory that a given acceleration-time product, creating a given change in whole head velocity $\Delta v$, will produce a given maximal strain in the brain. For falls from a particular height, we can estimate $\Delta \mathrm{v}$ as the velocity of a falling body at the Earth's surface from a particular height, h, which is $\Delta v=\sqrt{2 g h}$. For a grown man standing approximately 2 meters high this works out to be about $6 \mathrm{~m} / \mathrm{sec}$. Accounting for the weight of brain floating in CSF, such a fall would produce about $10 \%$ compressive strain or $5 \%$ elongation strain, and would be relatively safe from the point of view of experimental studies of stretched neurons ${ }^{25,45,46}$. 
In another study of safe accelerations reviewed by Marguiless and Thibault ${ }^{39}$, peak rotational acceleration and angular velocity following sub-concussive blows to the heads of volunteer boxers were recorded with specially instrumented helmets. These blows produced changes in rotational velocity of the head of $25 \mathrm{rad} / \mathrm{sec}$. For an effective radius of the neck of about 0.2 meters/radian in humans, the linear $\Delta v$ is $0.2 \times 25=5 \mathrm{~m} / \mathrm{sec}$, essentially the same value as for safe falls above.

Thus the buoyancy - strain wave analysis predicts accurately the qualitative features of brain motion, the degree of distortion for a given impulse, the speed of the compression wave, the particular sites of focal injury, the strength duration curve for production of concussion in primates, and the range of relatively safe levels of head acceleration in humans.

\subsection{Biology and evolution of the subdural space}

Understanding the role of the CSF in head injury also illuminates the evolutionary biology of the subarachnoid space. The width of the CSF (subdural or subarachnoid space) does not have to be great to provide buoyancy that reduces brain acceleration within the skull. Indeed a smaller CSF width would help minimize lateral expansion of the brain in response to a sudden blow to the head. However, a brain case design having near zero CSF width would not work because of the threat of brain edema. Even a small amount of brain swelling inside a closed box would drive up intracranial pressure enough to block capillary perfusion with blood. Furthermore, brain volume is well known to change as a function of local concentration of carbon dioxide. Hence there must be enough space for the brain to swell and shrink somewhat, with the CSF being vented by the arachnoid villi to provide a volumetric buffer. Thus the actual CSF width provides a balance between the need to limit transient lateral expansion of the brain in closed head injury and the need to permit gradual expansion of the brain in response to normal vasodilation or mild inflammation.

The comparative anatomy of the subdural space in fish, land mammals, and woodpeckers provides interesting insights. The animals in this sequence experience a spectrum jarring accelerations o the head. As shown in Figure 8 vertebrate species that live in water have subdural spaces surrounding the surface of the brain that are three to four fold wider relative to brain diameter than that those of vertebrate species that live on land ${ }^{47,48}$. Fish, frogs, and salamanders, which live in water, presumably experience no falls and much more damped whole body accelerations than do land animals. These data suggest that a more narrow CSF width may protect against deformation of the brain associated with whole head acceleration, which tends to be more violent in land animals.

\subsection{Implications for research}

The present analysis also suggests new approaches and animal models for future research. Assuming that positive elongation strain, that is stretching, of CNS neurons is 
the essential cause of closed head injury, one can investigate the underlying pathophysiology using isolated neurons, optic nerves, or spinal cord subjected to sudden stretching 44-46,49. Such preparations can be studied in terms of their function (nerve transmission) histopathology, membrane permeability, and responses to drugs. For many research questions such models would obviate the need for experiments involving impacting skulls of animals with falling weights, and the like, and would allow for easier, direct measurements and observations of neurophysiology, microanatomy, biochemistry and pharmacology, especially exploration of drug treatments to prevent secondary axotomy, that is damage that accumulates after initial mechanical injury and may be preventible by drugs ${ }^{43,50}$.

Another implication for research planning is that several meaningful questions can be addressed by studying material properties of fresh brain more carefully. For example, the possibility of shear between gray and white matter can be studied by doing experiments on the physical properties, density and stiffness, of freshly excised gray and white matter. The resulting values can be substituted into numerical models or analytical equations to predict relative motion of gray and white matter following sudden impacts to the head. Similar predictions can be made for ageing brains, alcoholic brains, and brain material excised after stroke or after prior head injury to test the hypothesis that these underlying conditions make the brain more vulnerable to concussion injury. One particular interest is whether softening (increased Young's modulus of elasticity, E) of brain after one concussion makes it more vulnerable to a second concussion, as suggested by the clinical literature ${ }^{51}$.

In conclusion, the buoyancy based models of brain motion within the skull during closed head injury make interesting and testable predictions about the nature and distribution of microanatomical lesions in closed head injury, the types of treatment that might be beneficial, and the kinds of experiments and animal models that might be helpful to develop new approaches for dealing with this significant public health problem. The ability to better understand and visualize the physics of brain deformation may also lead us to reevaluate society's somewhat casual attitude regarding minor head injury. 
Figures and Legends

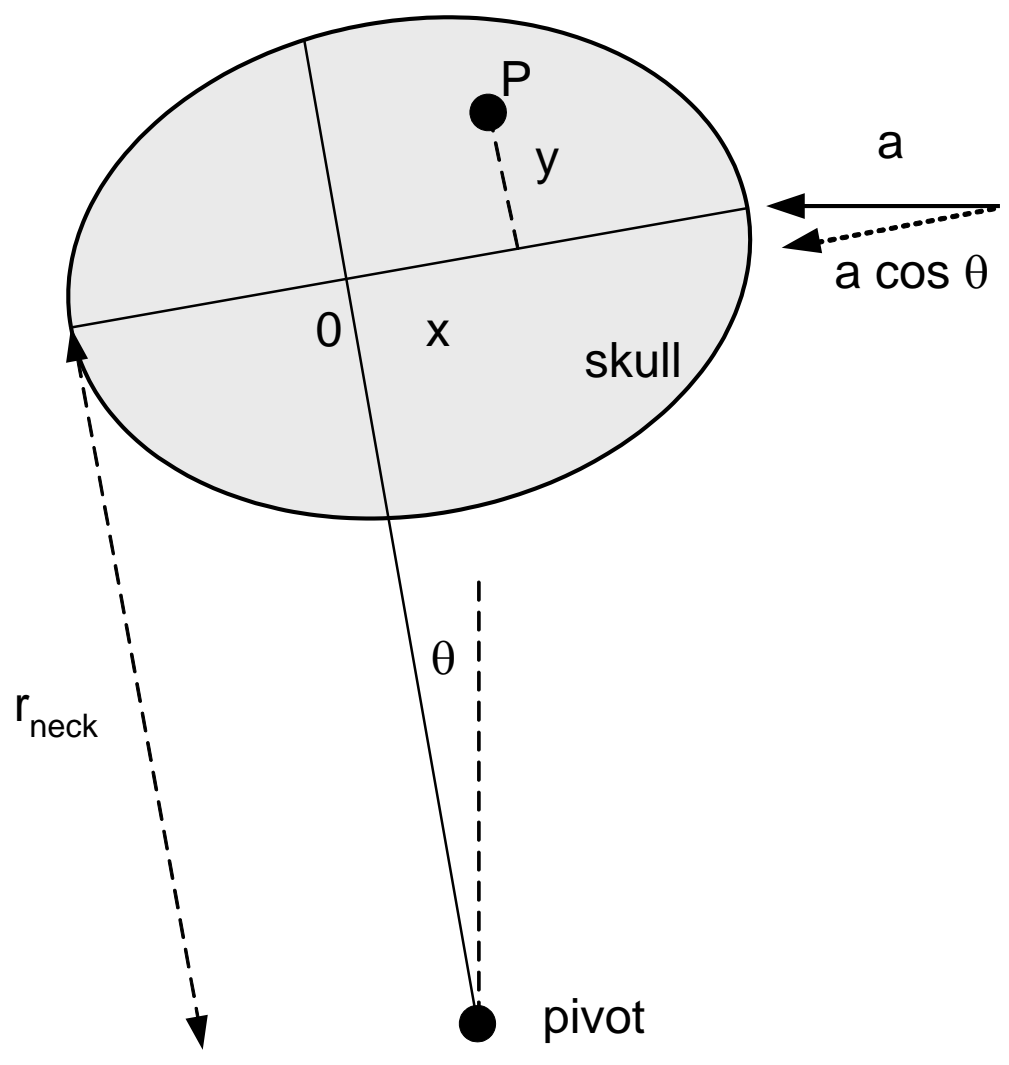

Figure 1. Internal frame of reference of the skull. The forehead is accelerated by a blow from the right with horizontal linear acceleration a. In response the head rotates backward through angle $\theta$, which remains small during the brief time of impact. As long as $\cos \theta \approx 1$ during impact, a mass at point, $\mathrm{P}$, feels acceleration toward the boundary of the skull having component magnitudes

$\ddot{x}=a \frac{r_{\text {neck }}+y}{r_{\text {neck }}}\left(1-\frac{\rho_{\mathrm{CSF}}}{\rho_{\text {brain }}}\right)$ and $\ddot{y}=-a \frac{x}{r_{\text {neck }}}\left(1-\frac{\rho_{\mathrm{CSF}}}{\rho_{\text {brain }}}\right)$. 


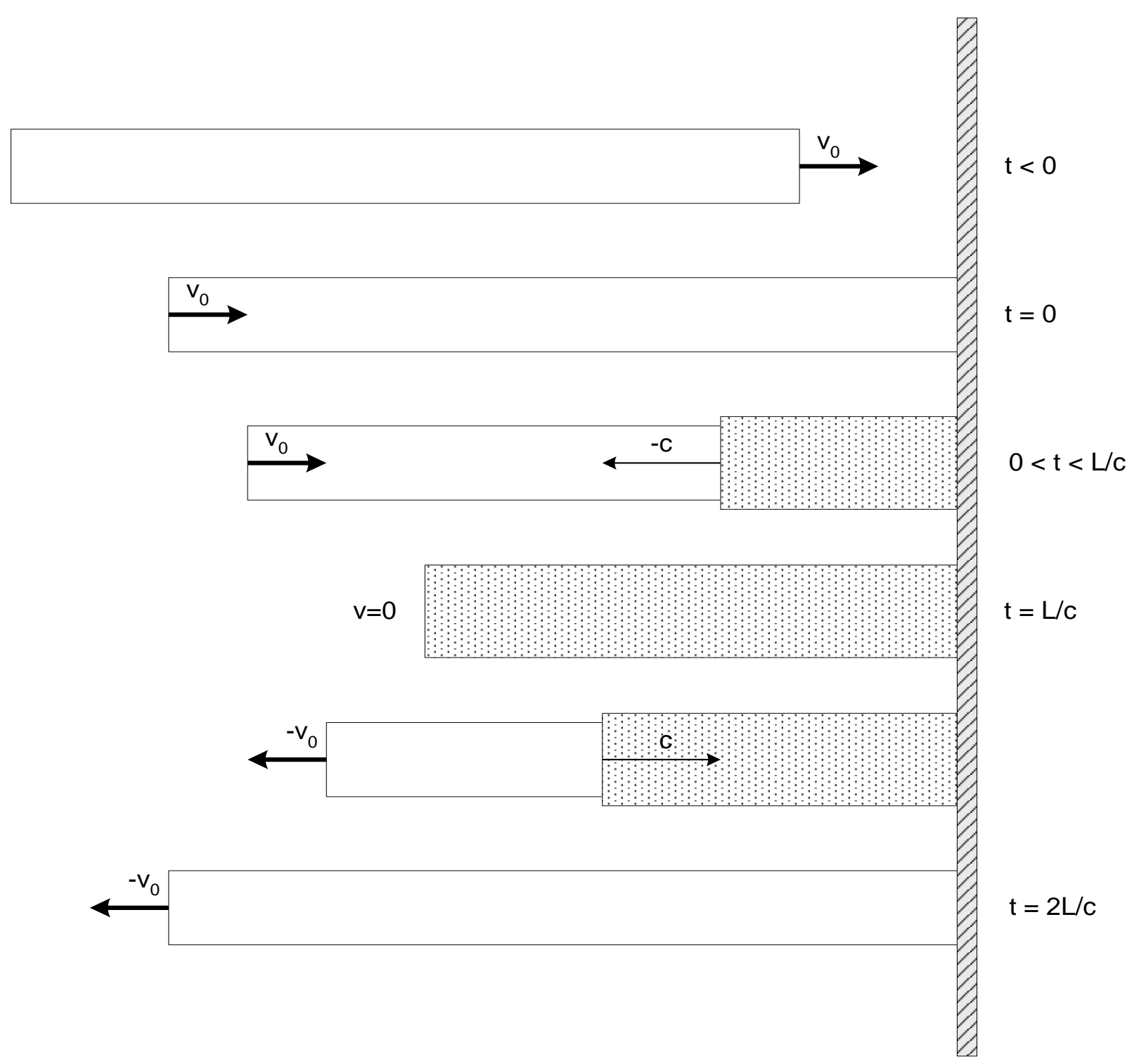

Figure 2. Phases of motion of an elastic bar hitting a solid wall with initial velocity, $\mathrm{v}_{0}$. Propagation of a compressive strain wave is shown at successive times after impact. The initial length of the bar is $L$. The strain wave velocity is $c=\sqrt{E / \rho}$. Typically $c>v_{0}$. 
(a)

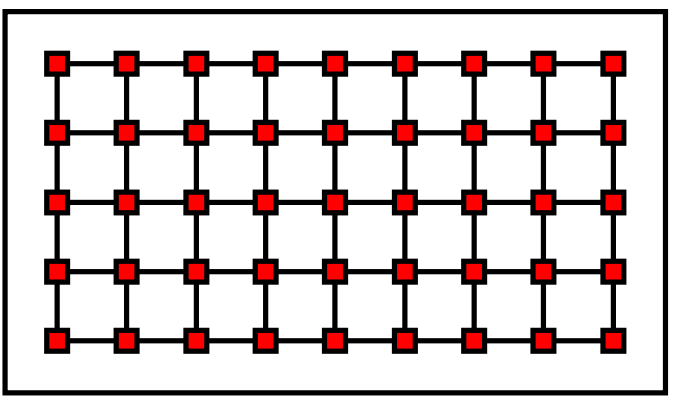

(b)

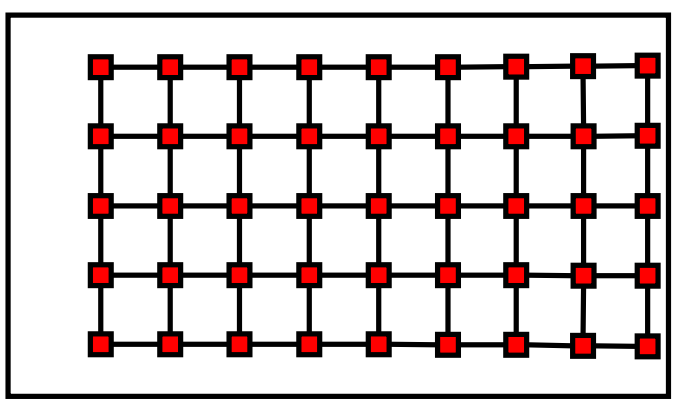

(c)

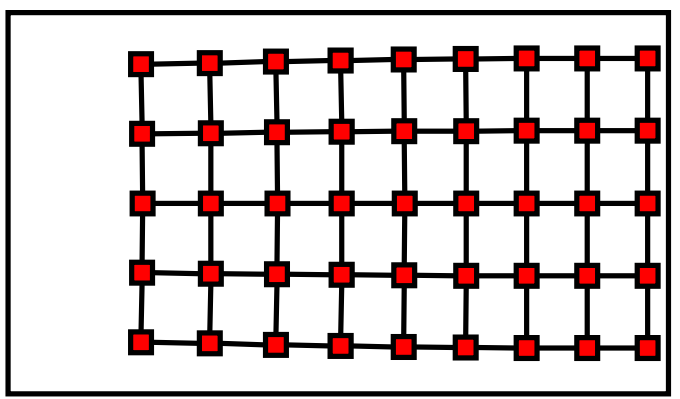

(d)

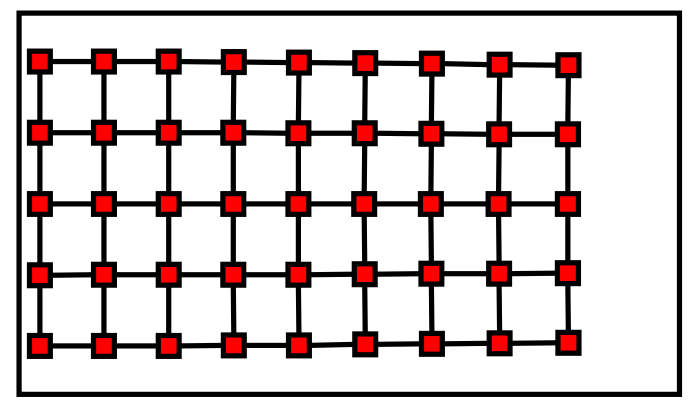

Figure 3. Computer animation of brain motion within a rectangular skull subjected to purely translational acceleration. (a) starting position $t=0$, (b) just after contact $t=0.03$ $\mathrm{sec}$, (c) near maximum crunch $\mathrm{t}=0.08 \mathrm{sec}$, (d) maximum crunch in contrecoup $\mathrm{t}=0.25$ sec. 
(a)

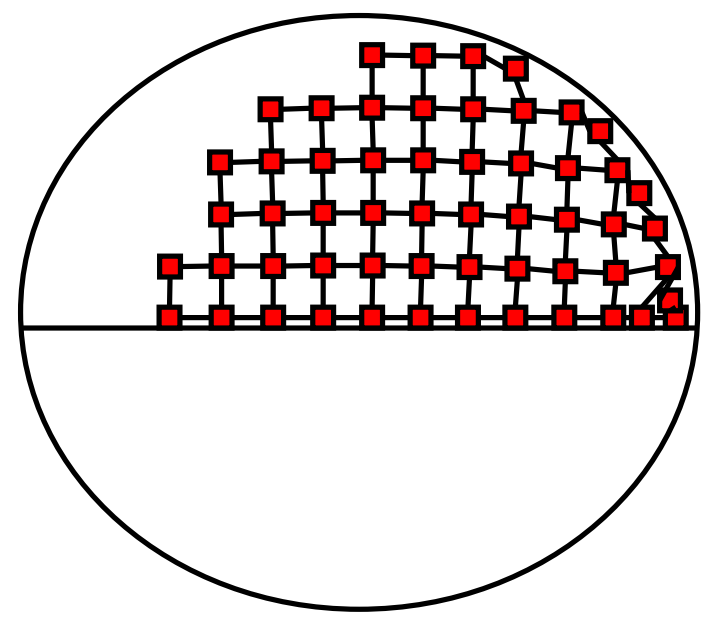

(b)

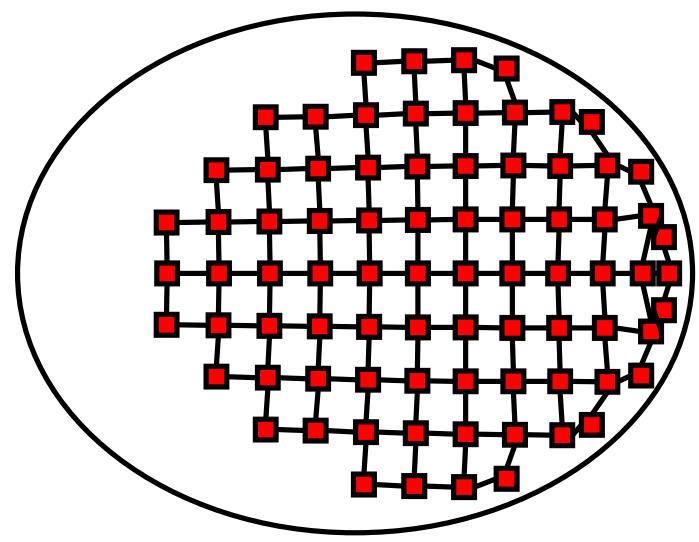

(c)

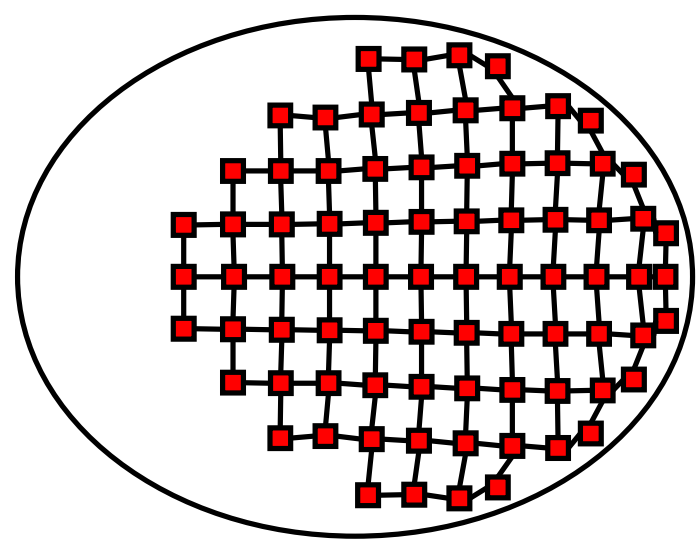

Figure 4. (a) Computer animation at maximal crunch within an ellipsoidal skull subjected to purely translational acceleration. $t=0.08 \mathrm{sec}(\mathrm{b})$ Similar animation with the geometry of an elliptical cylinder. The initiating blow produced $1000 \mathrm{~m} / \mathrm{sec}^{2}$ head acceleration and lasted $10 \mathrm{msec}$, near the threshold for concussion in humans. Localized compressive strains $>50 \%$ are evident near the pole. (c) Similar animation to (b) using non-linear expression for Young's modulus, E, of brain material as observed by Miller ${ }^{33}$. 
(a)

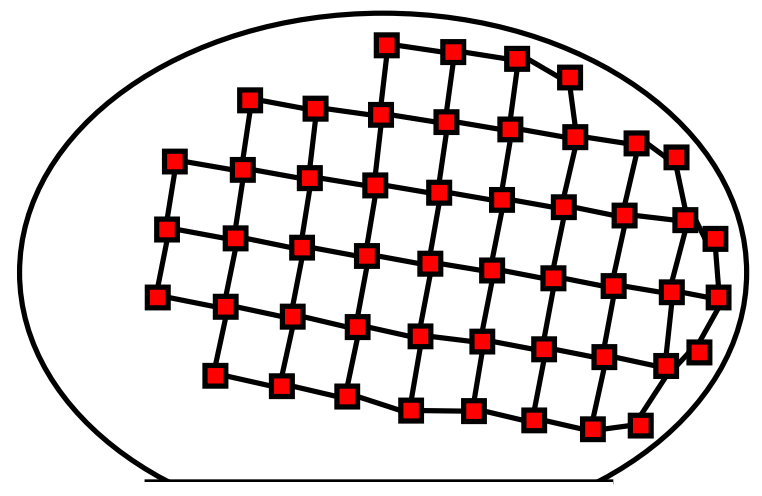

(b)

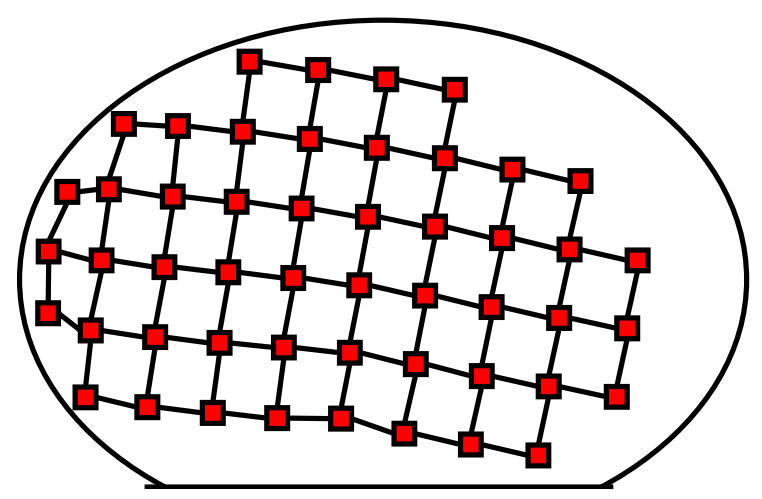

Figure 5. Motion and deformation of one cerebral hemisphere within the skull including both translational and rotational acceleration. (a) $t=0.08 \mathrm{sec}$ "coup", (b) $t=0.28 \mathrm{sec}$ "contrecoup". This model is a flattened ellipsoidal cylinder. The middle two nodes of the bottom row are partially tethered to reflect connection of the hemispheres with the midbrain. 
(a)

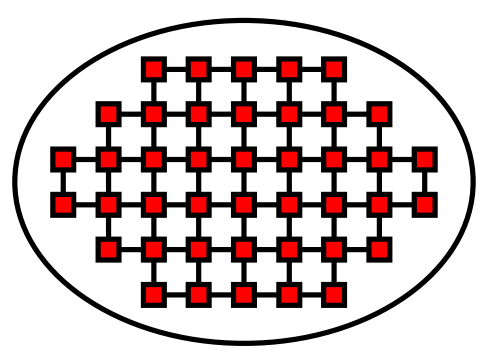

(b)

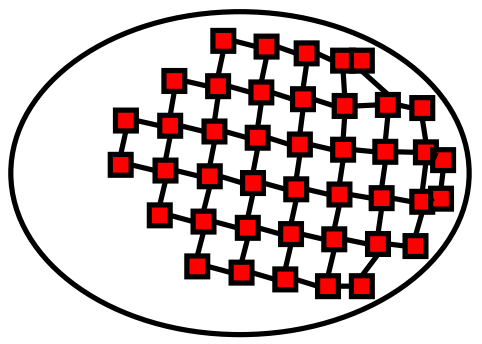

(c)

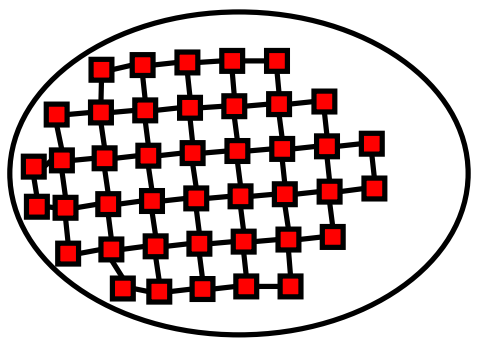

Figure 6. Computer animation of motion of structures in the posterior fossa, including cerebellum and pons. Threshold concussive impact to the forehead on the right began at $t$ $=0$. (a) $\mathrm{t}=0$ at initial position, (b) $\mathrm{t}=0.06 \mathrm{sec}$ at maximal initial crunch, showing severe compression in both $\mathrm{x}$ and $\mathrm{y}$ dimensions in the region of the transverse fibers of the pons and bulbar reticular formation. (c) $t=0.24 \mathrm{sec}$ showing maximum crunch at contrecoup in the region of the cerebellum. 
(a)

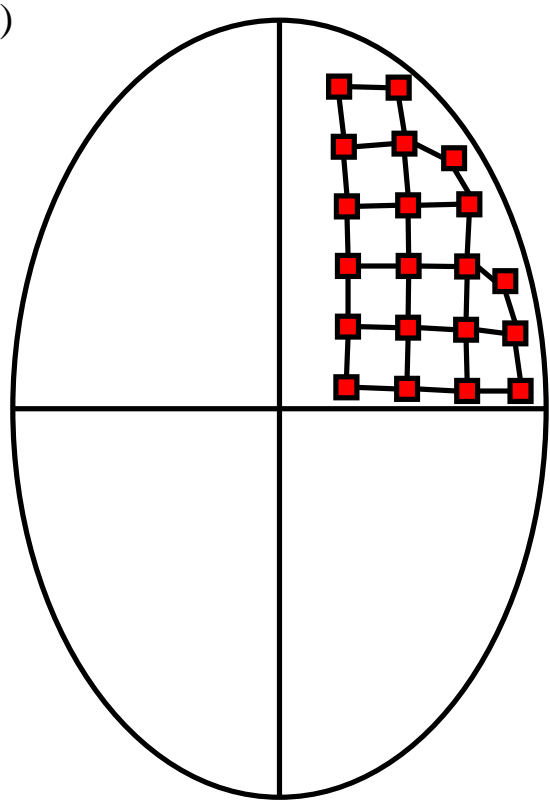

(b)

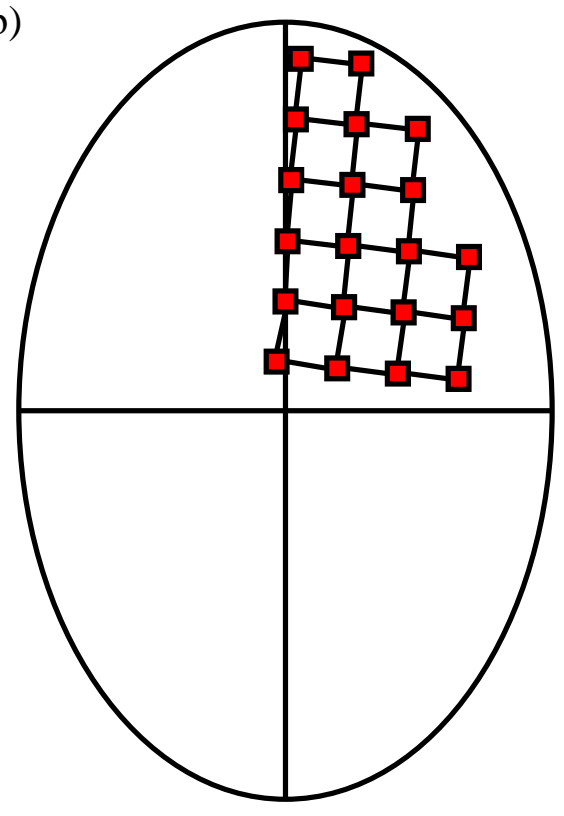

Figure 7. Computer animation of a lateral blow to the head of threshold concussive intensity. (a) $t=0.04 \mathrm{sec}$ initial crunch (b) $t=0.36 \mathrm{sec}$ contrecoup against the fal $\mathrm{x}$ cerebri, the bottom $3 \mathrm{~cm}$ of which is open, allowing the region of the corpus callosum (bottom row of nodes) to cross the midline. There is extra shear strain in the region of the corpus callosum. 


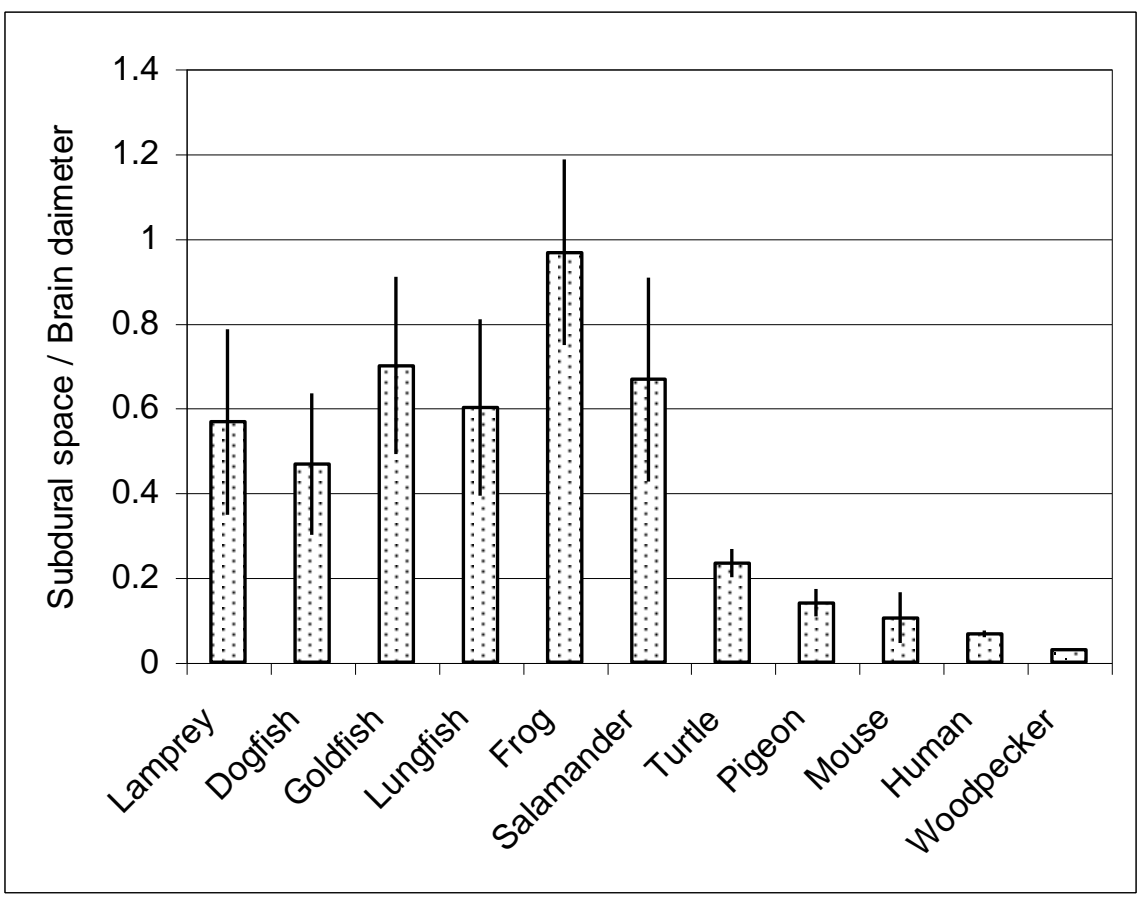

Figure 8. Ratios of subdural (subarachnoid) space thickness to brain diameter in various species taken from microscopic images published by Brockelhurst ${ }^{47,48}$ and for Woodpecker by $\mathrm{May}^{52}$. 


\section{$\underline{\text { Tables }}$}

Table 1. Nomenclature

A cross sectional area of brain model

$\mathrm{a}(\mathrm{t}) \quad$ brief, forceful acceleration of whole head due to external force

c strain wave propagation velocity through brain

$\mathrm{d}_{0} \quad$ original spacing of nodes in a Maxwell body or finite element model

d instantaneous distance between of nodes in a Maxwell body

D damping or loss modulus of brain tissue

E Young's modulus of elasticity of brain tissue

$\varepsilon \quad$ local strain in a model of the brain

$\varepsilon^{*} \quad$ a threshold harmful strain

F local force

g average acceleration of brain toward skull during impact based upon weight of brain in CSF water

$\mathrm{k} \quad$ spring constant of a dx length column of elastic material, namely $\mathrm{k}=\mathrm{AE} / \mathrm{dx}$

L longitudinal length of column of elastic material in brain model, i.e. brain dimension along the axis of linear acceleration

m mass

$\mu \quad$ damping constant of a dx length column of elastic material, namely $k=A D / d x$

$v \quad$ Poisson's ratio

@CSF mass density of cerebrospinal fluid

$\rho \quad$ mass density of brain

$\mathrm{R}, \mathrm{r} \quad$ neck radius 
s width of fluid filled gap between brain at rest and inner aspect of skull i.e. the distance traveled by the brain through CSF before brain-skull contact

$\tau \quad$ duration of acceleration impulse

$\hat{\tau} \quad$ duration of acceleration impulse ending at the instant the brain strikes the skull

$\mathrm{t}$ time

$\Delta \mathrm{t} \quad$ time step for numerical integration

V volume

$\theta \quad$ angle of brain rotation about a pivot point near the base of the neck

$\dot{\theta} \quad$ angular velocity

$\ddot{\theta} \quad$ angular acceleration

v velocity

$\mathrm{v}_{0} \quad$ velocity of brain toward skull at instant of brain-skull impact

$\mathrm{x} \quad$ longitudinal distance along axis of initial acceleration

$\mathrm{y}$ transverse distance perpendicular to the $\mathrm{x}$-axis

\section{Embellishments}

$\ddot{\mathrm{x}} \quad$ indicates acceleration in the $\mathrm{x}$ direction

$\dot{\mathrm{x}} \quad$ indicates velocity in the $\mathrm{x}$ direction 
Table 2. Viscoelastic properties of brain: measured values of Young's modulus of elasticity (E) and damping modulus (D) of brain near $1 \mathrm{~Hz}$ with 0 to $20 \%$ compressive strain.

\begin{tabular}{|r|r|r|r|}
\hline $\mathbf{E ~}(\mathbf{P a})^{\#}$ & $\mathbf{D} \mathbf{( P a - s e c}^{\#, *}$ & Investigator & Year \\
\hline 10,000 & 6 & Ommaya & 1968 \\
\hline 3,000 & 22 & Fallenstein & 1969 \\
\hline 15,000 & -- & Metz & 1970 \\
\hline 17,000 & 770 & Galford & 1970 \\
\hline 22,000 & 200 & Shuck & 1972 \\
\hline 11,000 & -- & Sahay & 1992 \\
\hline 8,000 & 180 & Donnelley & 1997 \\
\hline 5,000 & -- & Miller & 1997 \\
\hline 3,000 & -- & Miller & 2000 \\
\hline 8,000 & 400 & Babbs & 2003 \\
\hline & & & \\
\hline 10,200 & 260 & Mean & \\
$\pm 6,200$ & \pm 290 & \pm SD & \\
\hline 10,000 & 100 & Standard Model & \\
\hline
\end{tabular}

\# Representative median value for each study. These studies include a wide variability of biological samples and test techniques (relaxation, pure shear, compression, various loading rates, magnitude of applied strains, temperatures, post mortem changes in samples, or the use of pre-conditioning trials to establish repeatable results).

*Converted from shear moduli when necessary using $\mathrm{E} \approx 3 \mathrm{G}^{37,53}$. The damping modulus, D, is defined analogously to Young's modulus, namely the damping coefficient $\mu=\mathrm{DA} / \mathrm{L}$ for a block of viscoelastic material of cross sectional area A and length, L, parallel to the direction of compression or extension. The damping modulus, D, represents viscous losses in the material. 
Table 3. Measured values of brain density $(\rho)$

\begin{tabular}{|r|r|r|}
\hline $\boldsymbol{\rho}\left(\mathbf{g} / \mathbf{c m}^{\mathbf{3}}\right)$ & Investigator & Year \\
\hline $1.044^{\#}$ & Shigeno & 1982 \\
\hline $1.044^{*}$ & Shigeno & 1982 \\
\hline 1.040 & Duck & 1990 \\
\hline 1.044 & DiResta & 1991 \\
\hline 1.056 & Babbs & 2003 \\
\hline & & \\
\hline 1.046 & Mean & \\
\hline 1.046 & Standard Model & \\
\hline & & \\
\hline
\end{tabular}

\# Gray matter

* White matter

Table 4. Geometric parameters of the standard model

\begin{tabular}{|l|r|r|}
\hline Property & Cerebral cortex & $\begin{array}{r}\text { Mid pons and } \\
\text { cerebellum }\end{array}$ \\
\hline AP skull diameter $(\mathrm{cm})$ & $18^{*}$ & 10 \\
\hline CSF width $(\mathrm{cm})$ & 0.9 & 0.8 \\
\hline $\begin{array}{l}\text { Proportion of brain tissue } \\
\text { forward of neck axis }\end{array}$ & 0.6 & 0.3 \\
\hline Neck radius $(\mathrm{cm})$ & 20 & 15 \\
\hline Vertical axis ratio & $0.7^{\#}$ & 0.6 \\
\hline Horizontal axis ratio & 0.8 & 0.6 \\
\hline
\end{tabular}

* Assumed value

\# Without optional truncation 


\section{References}

1. Gurdjian ES. Head injury from antiquity to the present with special reference to penetrating head wounds. Springfield, IL: Charles C Thomas, 1973:24-25, 54-57, 72-75.

2. Kraus JF. Epidemiology of head injury. Head Injury 1993:1, 4-5,14,15,20-25.

3. Adams JH, Graham DI, Scott G, Parker LS, Doyle D. Brain damage in fatal nonmissile head injury. J Clin Pathol 1980; 33:1132-45.

4. Graham DI, Adams JH, Gennarelli TA. Pathology of brain damage in head injury. In: Cooper PR, ed. Head Injury. Balitmore: Williams \& Wilkins, 1993:91-113.

5. Gennarelli TA. Cerebral Concussion and Diffuse Brain Injuries. In: Cooper PR, ed. Head Injury. Baltimore: Williams \& Wilkins, 1993:137-158.

6. Strich S. Shearing of nerve fibers as a cause of brain damage due to head injury: a pathological study of twenty cases. The Lancet 1961; 2:443-448.

7. Dacey RG, Vollmer D, Dikmen S. Mild Head Injury. Head Injury 1993:159-165, 172-181.

8. Ommaya AK. Experimental head Injury in the monkey. In: Caveness WF, Walker AE, eds. Head Injury. Philadelphia: J B lippincott Company, 1966:260-275.

9. Adams JH, Graham DI, Gennarelli TA. Head injury in man and experimental animals: neuropathology. Acta Neurochir Suppl (Wien) 1983; 32:15-30.

10. Barth JT, Macciocchi SN, Giordani B, Rimel R, Jane JA, Boll TJ. Neuropsychological sequelae of minor head injury. Neurosurgery 1983; 13:52933.

11. Pudenz RH, Shelden $\mathrm{CH}$. The lucite calvarium-a method for direct observation of the brain. Journal of Neurosurgery 1946; 3:487-505.

12. Gosch HH, Gooding E, Schneider RC. Distortion and displacement of the brain in experimental head injuries. Surg Forum 1969; 20:425-6.

13. Gosch HH, Gooding E, Schneider RC. The lexan calvarium for the study of cerebral responses to acute trauma. J Trauma 1970; 10:370-6.

14. Hirsch AE. Current problems in head protection, Head Injury Conference, University of Chicago, 1966. J B Lippincott Company.

15. Ommaya AK, Fisch F, Mahone RM, P C, F L. Comparative tolerances for cerebral concussion by head impact and whiplash injury in primates.

Biomechanics 1993:265-274.

16. Lighthall JW, Melvin JW, K U. Toward a biomechanical criterion for functional brain injury. Biomechanics 1993:621-627.

17. Lockett FJ. Biomechanics justification for empirical head tolerance criteria. J Biomech 1985; 18:217-24.

18. Margulies SS, Thibault LE. An Analytical Model of Traumatic Diffuse Brain Injury. Biomechanical of Engineering 1989; 111:241-249.

19. Versace J. A review of the severity index, Proceedings of the 15th Stapp car crash conference, New York, 1971.

20. Kornhauser M, Lawton RW. Impact tolerance of mammals. In: Morrow CT, LeGalley DP, Ely LD, eds. Proceedings of the fourth AFBMD/STL symposium 
advances in ballistic missile and space technology. Vol. 3. Oxford: Permagon Press, 1961:368-394.

21. Pang D. Head Injury Rehabilitation: Children and Adolescents. In: Ylvisaker M, ed. San Diego: College-Hill Press, 1985:3-37, 66-70.

22. Willinger R, Kang HS, Diaw B. Three-dimensional human head finite-element model validation against two experimental impacts. Ann Biomed Eng 1999; 27:403-10.

23. Unterharnscheidt F, Sellier K. Mechanics and pathomorphology of closed brain injuries, Head Injury, Philadelphia, 1966. J B Lippincott Company.

24. Gross AG. A new theory on the dynamics of brain concussion and brain injury. $\mathrm{J}$ Neurosurg 1958; 15:548-61.

25. Meaney DF, Smith DH, Shreiber DI, et al. Biomechanical analysis of experimental diffuse axonal injury. J Neurotrauma 1995; 12:689-94.

26. Ivarsson J, Viano DC, P L. Influence of the lateral ventricles and irregular skull base on brain kinematics due to sagittal plane head rotation. ASME 2002; 124:422-431.

27. Nishimoto T, Murakami S. Relation Between Diffuse Axonal Injury and Internal Head Structures on Blunt Impact. Transactions of the ASME 1998; 120:140-147.

28. Ljung C. A model for brain deformation due to rotation of the skull. Biomechanics 1975; 8:263-264.

29. Bycroft GN. Mathematical model of a head subjected to an angular acceleration. J Biomech 1973; 6:487-95.

30. Rockey KC, Evans, Griffiths. The Finite Element Method: a Basic Introduction for Engineers. New York: Wiley, 1983:239 pages.

31. Jane JA, Steward O, Gennarelli T. Axonal degeneration induced by experimental noninvasive minor head injury. J Neurosurg 1985; 62:96-100.

32. Shigeno T, Brock M, Shigeno S, Fritschka E, Cervos-Navarro J. The determination of brain water content: microgravimetry versus drying-weighing method. J Neurosurg 1982; 57:99-107.

33. Miller K, Chinzei K. Constitutive modelling of brain tissue: experiment and theory. J Biomech 1997; 30:1115-21.

34. DiResta G, Lee J, Arbit E. Measurement of brain tissue specific gravity using pycnometry. Neuroscience 1991; 39:245-251.

35. Duck FA. Physical Properties of Tissue -- A Comprehensive Reference Book. London: Academic Press, 1990:226-245.

36. Feynman RP, Leighton RB, Sands M. The Feynman Lectures on Physics. Reading, Massachusetts: Addison-Wesley, 1964:38-1 to 38-5.

37. Fung YC. Biomechanics : mechanical properties of living tissues. New York: Springer-Verlag, 1981:23-57.

38. Brekhovskikh LM, Goncharov V. Mechanics of Continua and Wave Dynamics. Berlin: Springer-Verlag, 1994.

39. Margulies SS, Thibault LE. A proposed tolerance criterion for diffuse axonal injury in man. Biomechanics 1992; 25:917-923.

40. Gennarelli TA, Thibault LE, Adams JH, Graham DI, Thompson CJ, Marcincin RP. Diffuse axonal injury and traumatic coma in the primate. Ann Neurol 1982; 12:564-74. 
41. Adams JH, Doyle D, Ford I, Gennarelli TA, Graham DI, McLellan DR. Diffuse axonal injury in head injury: definition, diagnosis and grading. Histopathology 1989; 15:49-59.

42. Smith DH, Meaney DF. Axonal damage in traumatic brain injury. Progress in clinical neuroscience 2000; 6:483-495.

43. Povlishock JT, Becker DP, Miller JD, Jenkins LW, Dietrich WD. The morphopathologic substrates of concussion? Acta Neuropathol (Berl) 1979; 47:111.

44. Galbraith JA, Thibault LE, Matteson DR. Mechanical and electrical responses of the squid giant axon to simple elongation. J Biomech Eng 1993; 115:13-22.

45. Bain AC, Meaney DF. Thresholds for mechanical injury to the in vivo white matter. 43rd Stapp car crash conference proceedings 1999:295-302.

46. Gray JAB, Ritchie JM. Effects of stretch on single myelinated nerve fibers. J Physiol 1954:84-99.

47. Brocklehurst $\mathrm{G}$. The significance of the evolution of the cerebrospinal fluid system. Ann R Coll Surg Engl 1979; 61:349-56.

48. Brocklehurst G. The evolution of the cerebrospinal fluid (CSF) system. Vol. 2004, 2004.

49. Shi R, Pryor JD. Pathological changes of isolated spinal cord axons in response to mechanical stretch. Neuroscience 2002; 110:765-77.

50. Povlishock JT, Becker DP, Cheng CL, Vaughan GW. Axonal change in minor head injury. J Neuropathol Exp Neurol 1983; 42:225-42.

51. Cronwall D, Wrightson P. Cumulative effect of concussion. Lancet 1975; 2:995997.

52. May PR, Fuster JM, Newman P, Hirschman A. Woodpeckers and head injury. Lancet 1976; 1:454-5.

53. Muvdi BB, McNabb JW. Engineering mechanics of materials. New York: Springer-Verlag, 1991. 


\section{Appendices}

\section{Appendix 1. Forces on an interior node of an 8-way mesh}

With respect to Figure A1.1 consider interior node $\mathrm{P}$, located at point $(\mathrm{x}, \mathrm{y})$ in a two dimensional cartesian coordinate system, which is connected to 4 neighboring nodes, denoted N, S, E, W (for north, south, east, and west) by springs having spring constants $\mathrm{k}_{\mathrm{n}}, \mathrm{k}_{\mathrm{s}}, \mathrm{k}_{\mathrm{e}}$, and $\mathrm{k}_{\mathrm{w}}$ respectively. Initially and at rest the horizontal and vertical spacing of the nodes is a uniform distance, $\mathrm{d}_{0}$, and the springs exert zero force. However, due to possible distortion of the mesh, node $\mathrm{P}$ can be displaced from its equilibrium position to straight-line distances $d_{n}, d_{s}, d_{e}$, and $d_{w}$, from its neighbors at angles $\theta_{n}, \theta_{s}, \theta_{e}$ and $\theta_{w}$, as shown. Let $(\mathrm{x}, \mathrm{y})$ represent the spatial coordinates of node $\mathrm{P}$, and let $\left(\mathrm{x}_{\mathrm{n}}, \mathrm{y}_{\mathrm{n}}\right)$ represent the spatial coordinates of node $\mathrm{N},\left(\mathrm{x}_{\mathrm{e}}, \mathrm{y}_{\mathrm{e}}\right)$ the spatial coordinates of node $\mathrm{E}$, etc.

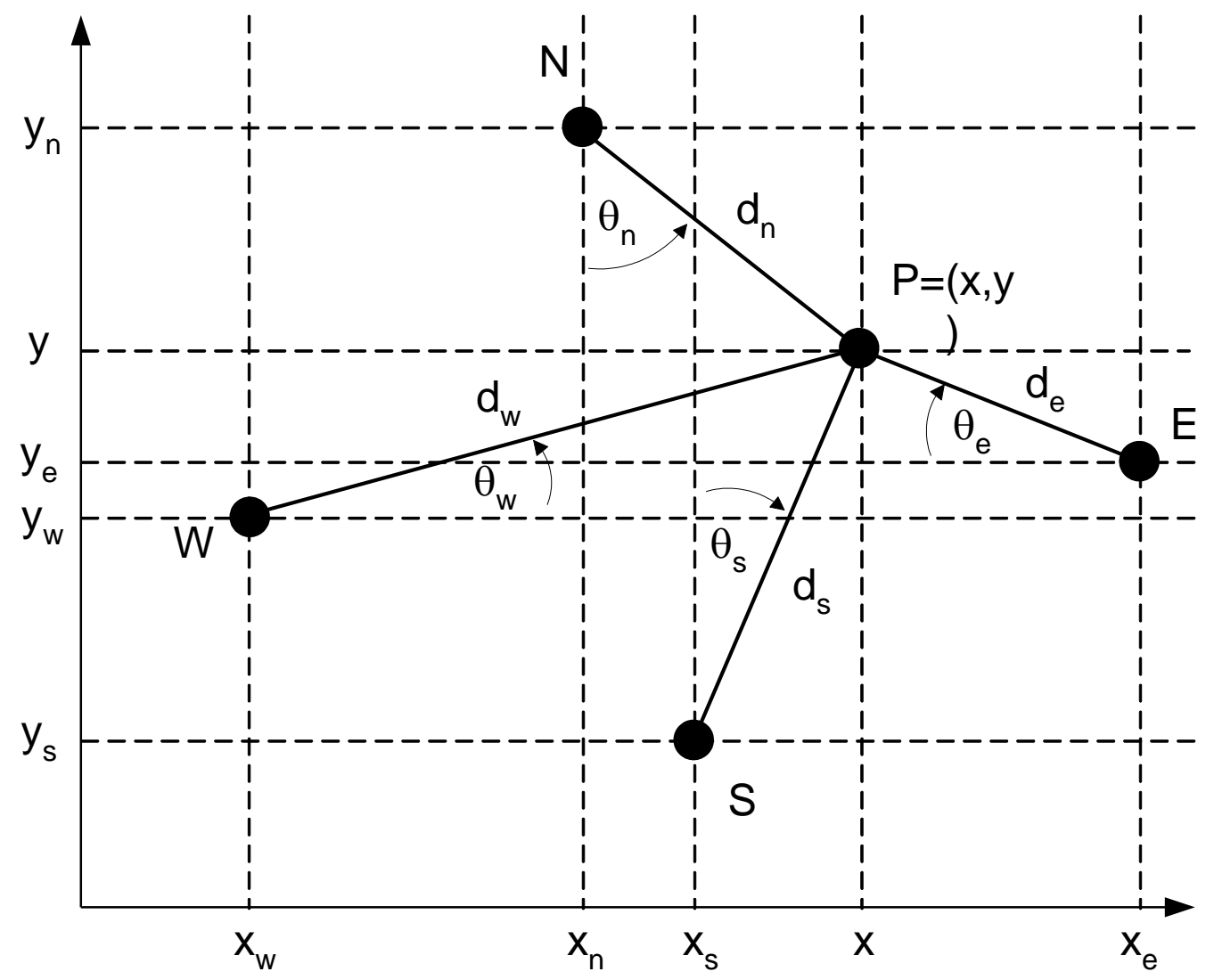

Figure A1.1

The vertical (y) force component on node $\mathrm{P}$ from the north spring is

$$
\mathrm{F}_{\mathrm{kyn}}=\mathrm{k}_{\mathrm{n}}\left(\mathrm{d}_{\mathrm{n}}-\mathrm{d}_{0}\right) \cos \theta_{\mathrm{n}}=\mathrm{k}_{\mathrm{n}}\left(\mathrm{d}_{\mathrm{n}}-\mathrm{d}_{0}\right)\left(\mathrm{y}_{\mathrm{n}}-\mathrm{y}\right) / \mathrm{d}_{\mathrm{n}}
$$


and similarly for the contributions from the south, east, and west springs. A similar expression is readily derived for the diagonal components from the northeast, southeast, southwest, and northwest springs in an 8-way mesh. Hence we can find the total vertical component of force from 8 neighboring springs on index node $\mathrm{P}$ as

$\mathrm{F}_{\mathrm{ky}}=\sum_{\mathrm{j}} \mathrm{k}_{\mathrm{j}}\left(\mathrm{d}_{\mathrm{j}}-\mathrm{d}_{0}\right)\left(\mathrm{y}_{\mathrm{j}}-\mathrm{y}\right) / \mathrm{d}_{\mathrm{j}}$

for $\mathrm{j}=\mathrm{n}, \mathrm{s}, \mathrm{e}, \mathrm{w}, \mathrm{ne}, \mathrm{se}, \mathrm{sw}$, and nw. For the diagonal neighbors replace $\mathrm{d}_{0}$ with $\mathrm{d}_{0} \sqrt{2}$.

The corresponding horizontal force component is

$$
\mathrm{F}_{\mathrm{kx}}=\sum_{\mathrm{j}} \mathrm{k}_{\mathrm{j}}\left(\mathrm{d}_{\mathrm{j}}-\mathrm{d}_{0}\right)\left(\mathrm{x}_{\mathrm{j}}-\mathrm{x}\right) / \mathrm{d}_{\mathrm{j}}
$$

The particular values of spring constants $\mathrm{k}_{\mathrm{j}}$ are found on the basis of Young's modulus of elasticity and the geometry of the mesh as shown in Appendix 2.

Forces due to dampers may be similarly calculated as follows. The force components from the damper connecting node $\mathrm{P}$ with node $\mathrm{N}$ are

$$
\mathrm{F}_{\mu x n}=\mu_{\mathrm{n}} \dot{\mathrm{d}}_{\mathrm{n}} \cos \theta_{\mathrm{n}}=\mu_{\mathrm{n}} \dot{\mathrm{d}}_{\mathrm{n}}\left(\mathrm{x}_{\mathrm{n}}-\mathrm{x}\right) / \mathrm{d}_{\mathrm{n}} \text { and } \mathrm{F}_{\mu y \mathrm{n}}=\mu_{\mathrm{n}} \dot{\mathrm{d}}_{\mathrm{n}}\left(\mathrm{y}_{\mathrm{n}}-\mathrm{y}\right) / \mathrm{d}_{\mathrm{n}}
$$

where the symbol $\dot{\mathrm{d}}$ represents the time derivative of straight line distance, $\mathrm{d}$.

The corresponding force components from all neighboring nodes are

$$
\mathrm{F}_{\mu \mathrm{x}}=\sum_{\mathrm{j}} \mu_{\mathrm{j}} \dot{\mathrm{d}}_{\mathrm{j}}\left(\mathrm{x}_{\mathrm{j}}-\mathrm{x}\right) / \mathrm{d}_{\mathrm{j}} \text { and } \mathrm{F}_{\mu \mathrm{y}}=\sum_{\mathrm{j}} \mu_{\mathrm{j}} \dot{\mathrm{d}}_{\mathrm{j}}\left(\mathrm{y}_{\mathrm{j}}-\mathrm{y}\right) / \mathrm{d}_{\mathrm{j}}
$$

for $\mathrm{j}=\mathrm{n}, \mathrm{s}, \mathrm{e}, \mathrm{w}, \mathrm{ne}, \mathrm{se}, \mathrm{sw}$, and nw, as before, with

$$
\dot{\mathrm{d}}_{\mathrm{j}}=\frac{\mathrm{d}\left(\mathrm{d}_{\mathrm{j}}\right)}{\mathrm{dt}}=\frac{\mathrm{d}}{\mathrm{dt}}\left(\sqrt{\left(\mathrm{x}-\mathrm{x}_{\mathrm{j}}\right)^{2}+\left(\mathrm{y}-\mathrm{y}_{\mathrm{j}}\right)^{2}}\right)=\frac{1}{\mathrm{~d}_{\mathrm{j}}}\left(\left(\mathrm{x}-\mathrm{x}_{\mathrm{j}}\right)\left(\dot{\mathrm{x}}-\dot{\mathrm{x}}_{\mathrm{j}}\right)+\left(\mathrm{y}-\mathrm{y}_{\mathrm{j}}\right)\left(\dot{\mathrm{y}}-\dot{\mathrm{y}}_{\mathrm{j}}\right)\right),
$$

and damping constants $\mu_{\mathrm{j}}$ defined as shown in Appendix 2.

\section{Appendix 2. Spring and damping constants in an 8-way mesh}

Diagonal spring constants: Figure A2.1 shows a sketch of a rectangular block of elastic material in shear. Shear is the type of deformation that happens when a deck of playing cards is displaced at an angle, represented here as $\alpha$. 


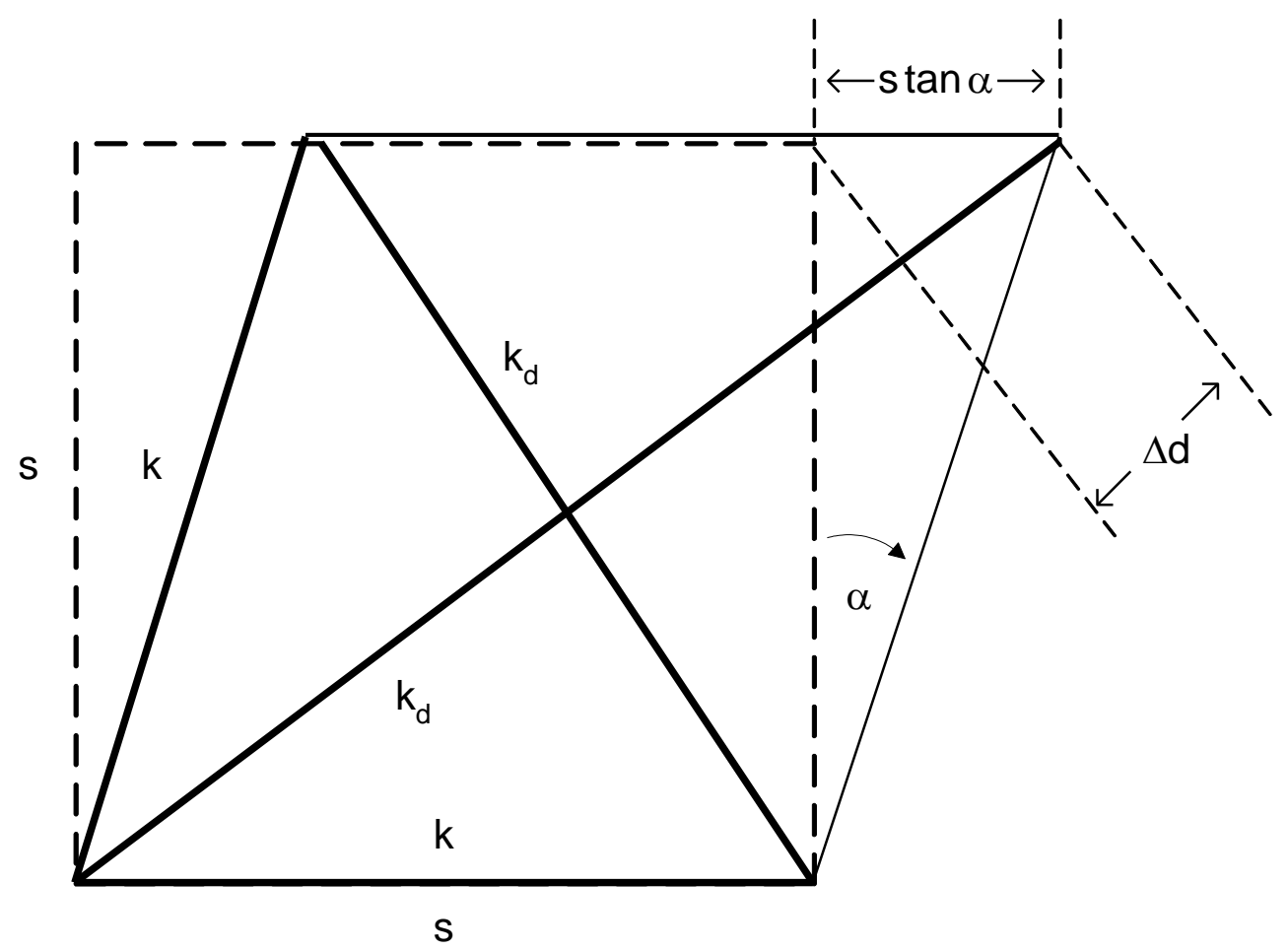

Figure A2.1

Consider small angles, $\alpha$, for which shear is resisted primarily by the diagonal springs, $\mathrm{k}_{\mathrm{d}}$ . There are two diagonal springs in each repeating unit of material. In the square twodimensional mesh the nodes are separated by distance, $s$. The cross sectional area of a repeating unit in the third dimension is A. For small angles, $\alpha$, the shear stress is defined as $\tau=\left(2 F_{d}+F_{o}\right) / A=G \tan \alpha \cong G \alpha$, where $F_{d}$ is the horizontal force resisting shear from one diagonal spring element, and $F_{o}$ is the force resisting shear from one vertical spring element. (The horizontal spring elements do not resist shear.) The constant $G$ is the modulus of rigidity, a property of the elastic material. If the change in length of the diagonal is $\Delta \mathrm{d} \approx(\operatorname{stan} \alpha) / \sqrt{2}$, then the shear force from one diagonal spring is $\mathrm{F}_{\mathrm{d}} \approx \mathrm{k}_{\mathrm{d}} \Delta \mathrm{d} / \sqrt{2} \approx \mathrm{k}_{\mathrm{d}} \mathrm{s} \alpha / 2$. The smaller shear force from one upright spring is $\mathrm{F}_{\mathrm{o}}=\mathrm{k}(\mathrm{s} / \cos \alpha-\mathrm{s}) \sin \alpha$. For small $\alpha$, we have $\cos \alpha \approx 1-\alpha^{2} / 2$, $\left(1-\alpha^{2} / 2\right)^{-1} \approx 1+\alpha^{2} / 2$, and $\sin \alpha \approx \alpha$. Hence $\mathrm{F}_{\mathrm{o}} \approx \mathrm{ks} \alpha^{3} / 2$. In turn the total shear Force is $\mathrm{G} \alpha \mathrm{A}=2 \mathrm{~F}_{\mathrm{d}}+\mathrm{F}_{\mathrm{o}} \approx \mathrm{k}_{\mathrm{d}} \mathrm{s} \alpha+\mathrm{ks}^{3} / 2 \approx \mathrm{k}_{\mathrm{d}} \mathrm{s} \alpha$. Thus we can solve for the diagonal spring constant $\mathrm{k}_{\mathrm{d}} \approx \mathrm{GA} / \mathrm{s}$ in terms of the fundamental material property $\mathrm{G}$. For a homogenous elastic solid $\mathrm{G}$ is related to Young's modulus of elasticity and Poisson's ratio by the expression $\mathrm{G}=\mathrm{E} /(2(1+v))^{37,53}$, so we can also express the diagonal spring constant in terms of Young's modulus $\mathrm{k}_{\mathrm{d}} \approx \frac{\mathrm{EA}}{\mathrm{s}} \cdot \frac{1}{2(1+v)}$ 
Normal spring constants: To find the constant, $\mathrm{k}$, describing the stiffness of horizontal and vertical springs in the 8-way mesh, we consider the force produced by vertical compression of the block of elastic material in Figure A2.2. The compressive strain $\varepsilon$ is taken as positive in sign and is accompanied by fractional lateral expansion of the material $v \varepsilon$, according to Poisson's ratio, $v$. Both springs in the cardinal directions and those on the diagonals contribute to the elastic properties of the 8-way mesh. First consider the case for small compressive strains, $\varepsilon$.

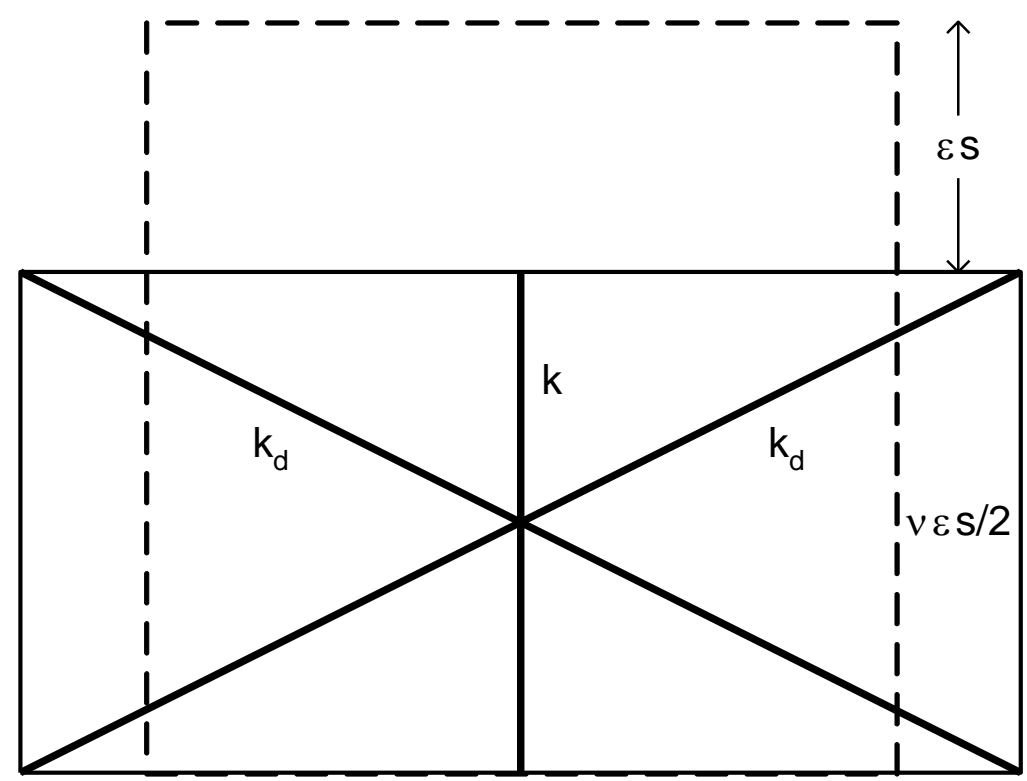

Figure A2.2

The total normal force generated is $\mathrm{F}_{\text {normal }}=\mathrm{ks} \varepsilon+2 \mathrm{k}_{\mathrm{d}}(-\Delta \mathrm{d}) / \sqrt{2}$. From the geometry of Figure $A 2.2$, it is readily show that for small strains $-\Delta \mathrm{d} \approx(1-v) \mathrm{s} \varepsilon / \sqrt{2}$, so we have $\mathrm{F}_{\text {normal }} \approx \mathrm{ks} \varepsilon+\mathrm{k}_{\mathrm{d}}(1-v) \mathrm{s} \varepsilon$. For a uniform elastic material we have Young's modulus of elasticity, $\mathrm{E}$, defined as $\mathrm{E}=\left(\mathrm{F}_{\text {normal }} / \mathrm{A}\right) / \varepsilon$, so that $\mathrm{AE}=\mathrm{F}_{\text {normal }} / \varepsilon$ or $\mathrm{AE}=\mathrm{ks}+\mathrm{k}_{\mathrm{d}}(1-\mathrm{v}) \mathrm{s}$, which can be solved for the normal spring constant, $k=A E / s-k_{d}(1-v)$. Now substituting for $\mathrm{k}_{\mathrm{d}}$ as derived in Appendix 1 and simplifying, we obtain

$\mathrm{k} \approx \frac{\mathrm{AE}}{\mathrm{s}}\left(\frac{1+3 v}{2(1+v)}\right)$

in terms of fundamental system parameters. For larger compressive strains a correction may derived (details not shown) that accounts for diagonal elements distorted to angles substantially different from 45 degrees or $\pi / 4$ radians, namely, 
$\mathrm{k} \approx \frac{\mathrm{AE}}{\mathrm{s}}\left(\frac{1+3 v}{2(1+v)}\right) \cdot\left(1+\frac{1-v}{1+v} \varepsilon\right)$

To maintain a given apparent Young's modulus $\mathrm{E}$ in the 8-way mesh for larger positive compressive strains, $\varepsilon>0$, spring constant k must be increased slightly, because the contributions of the flattened diagonal elements are less. However, for larger elongation strains, $\varepsilon<0$, spring constant k must be decreased slightly, because the contributions of the more parallel diagonal elements are greater. 